\title{
Model-Based Diagnosis and Fault Tolerant Control for Ensuring Torque Functional Safety of Pedal-by-Wire Systems
}

\author{
Jiyu Zhang*, Giorgio Rizzoni*, Andrea Cordoba-Arenas*, Alessandro

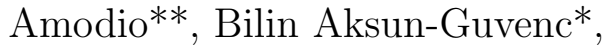 \\ *Department of Mechanical and Aerospace Engineering, Center for Automotive Research, \\ The Ohio State University, 930 Kinnear Rd, Columbus, Ohio 43212 \\ ** Politecnico di Milano, Dipartimento di Elettronica, Informazione e Bioingegneria, 5, \\ Via Ponzio, 34, 20133 Milano, Italia
}

\begin{abstract}
This paper presents a model based approach for defining automotive functional safety requirements and provides a solution to ensure functional safety through model-based diagnosis and fault tolerant control. This model-based approach is consistent with ISO26262 - functional safety standard. In particular, this paper presents the necessary steps for defining and implementing functional safety requirements, including item and function definition, hazard analysis and risk assessment, as well as the design of a model-based diagnostic and fault tolerant control (FTC) system that can lead to a systematic solution to automotive functional safety problems. The methodology proposed in this paper is applied to the problem of torque functional safety of pedal-by-wire systems.
\end{abstract}

Keywords: Functional safety, ISO26262, Model-based, Fault diagnosis, Fault tolerant control, Pedal-by-wire system 


\section{Introduction}

With the widespread use of on-board electrical and electronic (E/E) components and subsystems, the automotive industry has been facing increasingly critical safety challenges in the E/E system development process. To guarantee functional safety of various components and subsystems of a vehicle, the automotive industry has developed its own functional safety standard - ISO26262. The standard defines functional safety as "absence of unreasonable risk associated with each hazardous event caused by the malfunctioning behavior of E/E systems" [1, 2, 3]. Therefore, functional safety can be guaranteed by preventing or eliminating the risk of potential hazards. This is usually achieved by developing safety cases, which provide safety arguments, supported by sufficient evidence to show absence of unreasonable risk associated with each hazardous event. References [4, 5, 6] discuss safety case approaches for ensuring functional safety in compliance with ISO26262. In these references, a general framework for building safety cases is presented. A safety case must provide enough evidence to show that fault events can be safely managed, which requires the implementation of risk mitigation strategies if any component is detected to be faulty. However, the discussions on risk management and risk mitigation in these references are rather qualitative, and they do not address the problem on how the fault mitigation strategies can be practically designed and implemented to meet the functional safety goals.

This paper, on the other hand, proposes a quantitative approach using explicit models to implement automotive functional safety requirements. This approach not only helps define functional safety requirements in a quanti- 
tative way, but also introduces a model-based diagnosis and fault tolerant control approach that fulfills the functional safety requirements and leads to an integrated solution to functional safety problems.

ISO26262 relies on a "V-model" to represent each phase of a safety lifecycle [1. In this paper, an analogous approach is proposed to illustrate a model based approach for ensuring functional safety. It starts from functional safety requirements definition, and works through the design process of model-based diagnosis and fault tolerant control (FTC) system that leads to the implementation of diagnosis and FTC algorithms. The process is described by the V-model diagram in Fig. 1. The key elements of this approach include:

1. Item definition to clearly define the various components comprising a system as well as the functions they perform;

2. Hazard Analysis and Risk Assessment (HARA) to identify the various hazards and their Automotive Safety Integrity Level(ASIL);

3. Detailed plant and fault modeling to assist HARA so that a suitable ASIL is assigned for each considered hazard and safety goals are set;

4. The technical design of a model-based fault diagnosis and FTC approach that is generally applicable to any systems performing safety functions, in particular, the various steps of implementation, calibration and validation of the diagnostic and fault tolerant control functions;

5. Functional safety assessment of the diagnostic and FTC strategies to 
ensure functional safety goals.

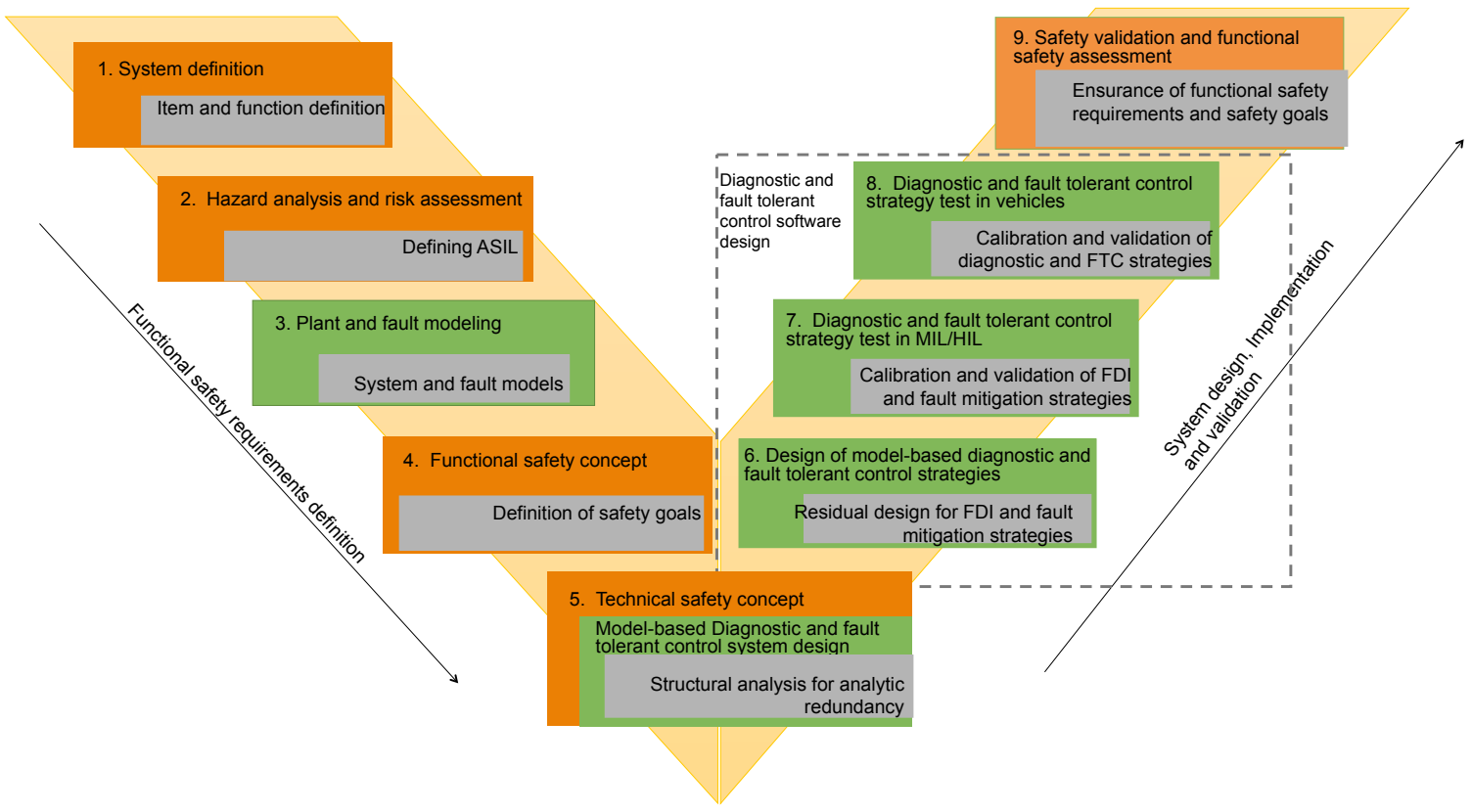

Figure 1: A systematic model-based methodology for automotive functional safety through model-based diagnosis and fault tolerant control

This paper studies the necessary steps for achieving functional safety using this model-based approach, and presents a case study on torque functional safety of electrified vehicles, though the methods developed would be applicable to any pedal-by-wire systems, regardless of powertrain type. The torque functional safety problem, also referred to as sudden unintended acceleration in this paper, is defined as the occurrence of unintended, unexpected, high-power accelerations starting from a stationary position or a very low initial speed accompanied by an apparent loss of braking effectiveness [7]. This paper shows that the proposed model-based approach can be used to define 
a quantitative functional safety goal related to torque functional safety for pedal-by-wire systems in electrified vehicles, and studies how model-based diagnosis and FTC can help achieve the goal to avoid unreasonable risk associated with unintended acceleration event.

Model-based diagnosis has the advantage of providing a deep understanding of the process behavior and is effective in detecting incipient faults [8, 9]. In particular, this paper presents a model-based diagnostic tool which is referred as structural analysis for Fault Detection and Isolation (FDI), which is a methodology that uses the structural model of a system to identify the analytic redundant relations in the system model, leading to a systematic approach to fault diagnosis [10, 11]. One advantage of the structural FDI approach is that it does not depend on specific numerical parameters, but it depends on the structure of the model, as is shown later in the paper. Therefore, it is applicable in the early stages of the design process to any diagnostic system, even when the final system specifications are not determined. A further advantage of the structural analysis approach is that it decomposes a complex system into smaller subsystems. This decomposition allows for efficient design of diagnostic algorithms that are more easily implementable. This approach is especially useful in diagnosis of large complex systems such as automobiles.

The structural FDI approach has been well developed in the literature, mostly with focus on its theoretical development, for example in references [12, 13, 14, 15, 16]. As to the application side, structural FDI has been applied to engine systems[17, 18, 19], battery systems [20], hybrid vehicle systems [21, 22], and permanent magnet synchronous machine (PMSM) drive systems 
[23, 24]. The structural analysis approach has proven to be an efficient tool in analyzing the fault detectability and isolability in a complex engineering model, and provides guidance to the architecture of diagnostic algorithms for fault detection and isolation. The work presented in this paper is the first in which structural analysis is linked to the torque functional safety problem. This paper develops FDI and FTC strategies based on structural analysis to show its application to solve the torque functional safety problem and therefore to ensure functional safety.

This paper is organized as follows: Section 2 presents a systematic model based approach for functional safety. The section covers the relevant aspects of ISO26262, using an electrified powertrain as an example. Section 3 introduces a safety case of torque functional safety of pedal-by-wire systems in electrified vehicles. In particular, a structural approach for FDI and FTC is introduced to identify the fault location and mitigate the effects of faults in order to achieve torque functional safety. Then, simulation results are presented to show the effectiveness of the proposed FDI and FTC strategies. Finally in the section, functional safety assessment are presented to show that the safety goal can be met using the proposed strategies.

\section{A Systematic Model Based Approach to Achieve Functional Safety}

\subsection{Item and Function Definition}

The first step in the ISO26262 concept phase is to define and describe an item including their elements and the associated functions. Fig. 2 shows the diagram of an electrified powertrain, whose main function is to deliver 
torque as requested by the driver.

As can be seen, the electrified powertrain is comprised of a supervisory controller that receives driver commands (accelerator pedal position $\alpha$ or brake pedal position $\beta$ ) and converts them into a torque request $\left(T_{e}\right)$, which is then sent to the electric drive system to drive the wheels [25]. A typical electric drive system in an electrified vehicle consists of a battery source, an electric machine (which can be both used as a motor when the vehicle is accelerating or cruising, or as a generator when the vehicle is braking or coasting), an inverter that converts the DC voltage to three phase AC voltages in order to drive an $\mathrm{AC}$ machine, and a EM controller that controls the torque output from the electric machine as requested. The components and their functions in this electrified powertrain are defined in Table 1 .

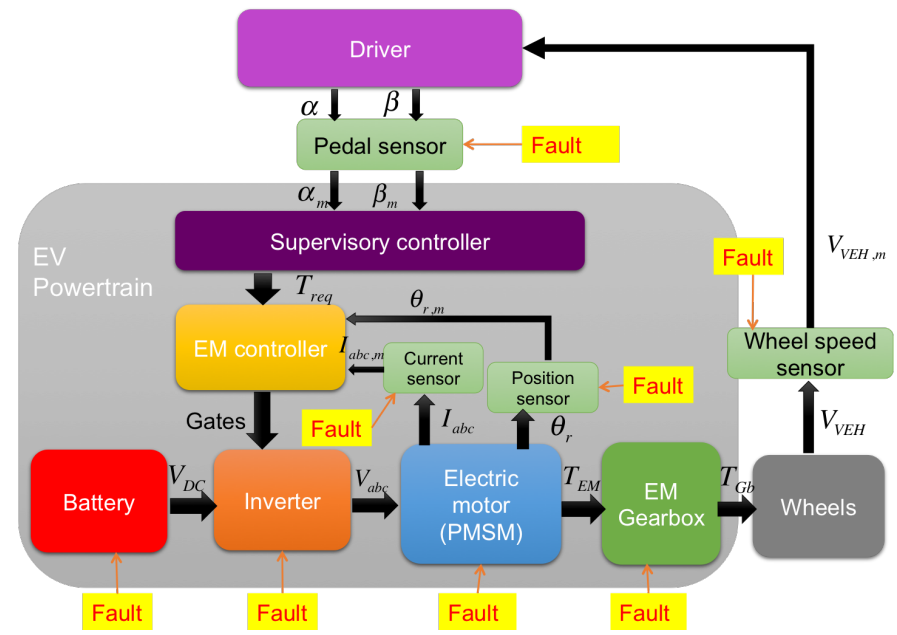

Figure 2: Electric drive system in an electric vehicle

\subsection{Hazard Analysis and Risk Assessment (HARA)}

The next step of the ISO26262 concept phase is HARA. The purpose of this step is to identify and assess/classify all the potential hazards caused by 


\begin{tabular}{|l|l|}
\hline Component & Function \\
\hline Driver & $\begin{array}{l}\text { Gives accelerating/braking command by pressing } \\
\text { accelerator or brake pedals }\end{array}$ \\
\hline Accelerator pedal sensor & $\begin{array}{l}\text { Senses pedal positions and sends a signal to the } \\
\text { supervisory controller }\end{array}$ \\
\hline Supervisory controller & Converts sensor readings to a torque request \\
\hline EM controller & $\begin{array}{l}\text { Converts supervisory torque request to gating signals } \\
\text { in the power converter drive module using Pulse Width } \\
\text { Modulation (PWM) techniques }\end{array}$ \\
\hline Inverter & $\begin{array}{l}\text { Converts the DC voltage from the battery into three } \\
\text { phase AC voltages in order to drive a AC machine }\end{array}$ \\
\hline Electric machine & Delivers torque to the vehicle drivetrain \\
\hline EM gearbox & Magnifies the EM torque to drive the wheels \\
\hline Wheel speed sensor & $\begin{array}{l}\text { Reads the vehicle speed and sends it to the supervisory } \\
\text { controller }\end{array}$ \\
\hline
\end{tabular}

Table 1: Item and function definition for electrified powertrains

the malfunctions of $\mathrm{E} / \mathrm{E}$ elements [1]. In this step, a safety goal is defined for each considered hazard as top-level safety requirements. In [26], the authors use the Failure Modes and Effect Analysis (FMEA) approach to carry out a hazard analysis for the key components of an electrified powertrain. For each hazard, ISO26262 assigns an ASIL, classified by the five levels: QM, A, B, C, D, where, D represents the highest level which requires the greatest effort to reach safety goals; A stands for the lowest risk and requires the least effort; and QM stands for quality management, which means that no additional action is required beyond quality management.

In ISO26262, as shown in Fig. 3, the ASIL of a hazardous event is determined considering the estimation of its impact factors: severity of the hazard 
impact on humans ( $\mathrm{S}=$ severity), probability of exposure of the operational situation in which the hazardous event could occur $(\mathrm{E}=$ exposure $)$ and the ability to avoid a specified harm or damage through the timely reactions of the humans involved ( $\mathrm{C}=$ controllability).

\begin{tabular}{|c|c|c|c|c|}
\hline \multirow{2}{*}{ Severity class } & \multirow{2}{*}{ Probability class } & \multicolumn{3}{|c|}{ Controllability class } \\
\hline \multirow{3}{*}{ S1 } & E1 & Q1 & C2 & C3 \\
\cline { 2 - 5 } & E2 & QM & QM & QM \\
\cline { 2 - 5 } & E3 & QM & QM & QM \\
\cline { 2 - 5 } & E4 & QM & A & B \\
\hline \multirow{3}{*}{ S2 } & E1 & QM & QM & QM \\
\cline { 2 - 5 } & E2 & QM & QM & A \\
\cline { 2 - 5 } & E3 & QM & A & B \\
\cline { 2 - 5 } & E4 & A & B & C \\
\hline \multirow{3}{*}{ S3 } & E1 & QM & QM & A \\
\cline { 2 - 5 } & E2 & QM & A & C \\
\cline { 2 - 5 } & E3 & A & B & D \\
\cline { 2 - 5 } & E4 & B & C & \\
\hline
\end{tabular}

Figure 3: ASIL determination [1]

Severity is classified in four levels by $\mathrm{S} 0 \sim \mathrm{S} 3$, where $\mathrm{S} 0$ means no injuries and S3 stands for life-threatening injuries; exposure is classified as E0 E4, where E0 means incredible, while E4 means very high probability; controllability ranks from $\mathrm{C} 0 \sim \mathrm{C} 3$, where $\mathrm{C} 0$ means controllable in general, while C3 represents difficult to control or uncontrollable.

Based on the studies conducted in [27, 28, 29, 30], a preliminary hazard analysis and risk assessment for electrified vehicle torque functional problem can be conducted as shown in Table. 2 


\begin{tabular}{|c|c|c|c|c|c|c|c|c|c|}
\hline Component & $\begin{array}{l}\text { Potential } \\
\text { Failure } \\
\text { Modes }\end{array}$ & $\begin{array}{l}\text { Potential } \\
\text { Conse- } \\
\text { quences of } \\
\text { Failure } \\
\end{array}$ & $\mathrm{S}$ & $\mathrm{E}$ & $\mathrm{C}$ & ASIL & $\begin{array}{l}\text { Potential } \\
\text { Causes of } \\
\text { Failure }\end{array}$ & Safety goal & $\begin{array}{l}\text { Recommended } \\
\text { action }\end{array}$ \\
\hline $\begin{array}{l}\text { Accelerator } \\
\text { pedal }\end{array}$ & $\begin{array}{l}\text { Accelerator } \\
\text { pedal too } \\
\text { sensitive }\end{array}$ & $\begin{array}{l}\text { Vehicle } \\
\text { lurches } \\
\text { forward } \\
\text { when } \\
\text { starting }\end{array}$ & 2 & 4 & 2 & B & $\begin{array}{l}\text { Accelerator } \\
\text { pedal gain is } \\
\text { too large }\end{array}$ & $\begin{array}{c}\text { Avoid } \\
\text { unintended } \\
\text { accelerating } \\
\text { torque }\end{array}$ & $\begin{array}{c}\text { Power limiting of } \\
\text { the accelerator } \\
\text { pedal }\end{array}$ \\
\hline $\begin{array}{c}\text { Accelerator } \\
\text { pedal }\end{array}$ & $\begin{array}{c}\text { Accelerator } \\
\text { pedal stuck } \\
\text { at partially } \\
\text { depressed } \\
\text { position }\end{array}$ & $\begin{array}{l}\text { Vehicle keeps } \\
\text { accelerating } \\
\text { when } \\
\text { accelerator } \\
\text { pedal is } \\
\text { released } \\
\end{array}$ & 2 & 4 & 3 & C & $\begin{array}{l}\text { Accelerator } \\
\text { blocked by } \\
\text { foreign } \\
\text { object; } \\
\text { Mechanical } \\
\text { failure } \\
\end{array}$ & $\begin{array}{c}\text { Avoid } \\
\text { unintended } \\
\text { accelerating } \\
\text { torque }\end{array}$ & $\begin{array}{c}\text { Power limiting of } \\
\text { the accelerator } \\
\text { pedal, accelerator } \\
\text { pedal override by } \\
\text { pressing brake } \\
\text { pedal }\end{array}$ \\
\hline $\begin{array}{l}\text { Accelerator } \\
\text { pedal }\end{array}$ & $\begin{array}{l}\text { Sticky pedal: } \\
\text { harder to } \\
\text { depress and } \\
\text { slower to } \\
\text { release }\end{array}$ & $\begin{array}{c}\text { Vehicle } \\
\text { decelerates } \\
\text { more slowly } \\
\text { than desired }\end{array}$ & 2 & 4 & 2 & B & $\begin{array}{l}\text { Mechanical } \\
\text { fatigue }\end{array}$ & $\begin{array}{c}\text { Avoid } \\
\text { unintended } \\
\text { accelerating } \\
\text { torque }\end{array}$ & $\begin{array}{l}\text { Accelerator pedal } \\
\text { override by } \\
\text { pressing brake } \\
\text { pedal }\end{array}$ \\
\hline $\begin{array}{l}\text { Brake } \\
\text { system }\end{array}$ & $\begin{array}{l}\text { Components } \\
\text { failure (i.e. } \\
\text { leakage in } \\
\text { master } \\
\text { cylinder or } \\
\text { brake lines) }\end{array}$ & $\begin{array}{l}\text { Inadequate } \\
\text { braking }\end{array}$ & 3 & 4 & 2 & $\mathrm{C}$ & $\begin{array}{c}\text { Mechanical } \\
\text { break }\end{array}$ & $\begin{array}{l}\text { Avoid loss of } \\
\text { braking } \\
\text { torque }\end{array}$ & $\begin{array}{c}\text { Use electric } \\
\text { motor brake and } \\
\text { park brake to } \\
\text { replace the } \\
\text { hydraulic brakes }\end{array}$ \\
\hline $\begin{array}{l}\text { Brake } \\
\text { system }\end{array}$ & Brake fade & $\begin{array}{l}\text { Reduction of } \\
\text { brake } \\
\text { effectiveness } \\
\text { or not } \\
\text { enough } \\
\text { brake power }\end{array}$ & 3 & 4 & 3 & $\mathrm{D}$ & $\begin{array}{l}\text { Thermal or } \\
\text { mechanical } \\
\text { stresses due } \\
\text { to repeated } \\
\text { use of brake } \\
\text { components }\end{array}$ & $\begin{array}{l}\text { Avoid loss of } \\
\text { braking } \\
\text { torque }\end{array}$ & $\begin{array}{l}\text { Use electric } \\
\text { motor brake and } \\
\text { park brake to } \\
\text { replace the } \\
\text { hydraulic brakes }\end{array}$ \\
\hline $\begin{array}{l}\text { Brake } \\
\text { pedal }\end{array}$ & $\begin{array}{l}\text { Brake pedal } \\
\text { is stuck, slow } \\
\text { or hard to } \\
\text { press }\end{array}$ & $\begin{array}{c}\text { Slow or } \\
\text { inadequate } \\
\text { braking } \\
\text { response }\end{array}$ & 3 & 4 & 3 & $\mathrm{D}$ & $\begin{array}{c}\text { Mechanical } \\
\text { break }\end{array}$ & $\begin{array}{l}\text { Avoid loss of } \\
\text { braking } \\
\text { torque }\end{array}$ & $\begin{array}{l}\text { Vehicle shut } \\
\text { down }\end{array}$ \\
\hline $\begin{array}{l}\text { Pedal } \\
\text { position } \\
\text { sensor }\end{array}$ & $\begin{array}{l}\text { Higher } \\
\text { readings } \\
\text { than normal }\end{array}$ & $\begin{array}{l}\text { Supervisory } \\
\text { controller } \\
\text { calculates } \\
\text { higher } \\
\text { torque } \\
\text { commands } \\
\text { than desired } \\
\end{array}$ & 2 & 4 & 3 & $\mathrm{C}$ & $\begin{array}{l}\text { Electrical } \\
\text { failures such } \\
\text { as short } \\
\text { circuit }\end{array}$ & $\begin{array}{c}\text { Avoid } \\
\text { unintended } \\
\text { accelerating } \\
\text { torque }\end{array}$ & $\begin{array}{l}\text { Limp home } \\
\text { mode, use } \\
\text { remaining pedal } \\
\text { sensor }\end{array}$ \\
\hline $\begin{array}{l}\text { Cruise } \\
\text { control }\end{array}$ & $\begin{array}{l}\text { Failure of } \\
\text { Cruise } \\
\text { Control } \\
\text { switches }\end{array}$ & $\begin{array}{c}\text { Cruise } \\
\text { Control is } \\
\text { initiated } \\
\text { when not } \\
\text { desired or } \\
\text { not canceled } \\
\text { at request } \\
\end{array}$ & 3 & 2 & 1 & QM & $\begin{array}{l}\text { Short or } \\
\text { ground in } \\
\text { the electrical } \\
\text { circuit }\end{array}$ & $\begin{array}{l}\text { Avoid loss of } \\
\text { control on } \\
\text { the vehicle }\end{array}$ & $\begin{array}{l}\text { Cancel cruise by } \\
\text { pressing the } \\
\text { brake or shift to } \\
\text { neutral }\end{array}$ \\
\hline $\begin{array}{l}\text { Cruise } \\
\text { control }\end{array}$ & $\begin{array}{l}\text { Brake switch } \\
\text { stuck off }\end{array}$ & $\begin{array}{c}\text { Cruise } \\
\text { Control is } \\
\text { not canceled } \\
\text { when the } \\
\text { driver pushes } \\
\text { brake pedal }\end{array}$ & 3 & 2 & 1 & $\mathrm{QM}$ & $\begin{array}{l}\text { Short or } \\
\text { ground in } \\
\text { the electrical } \\
\text { circuit }\end{array}$ & $\begin{array}{l}\text { Avoid loss of } \\
\text { control on } \\
\text { the vehicle }\end{array}$ & $\begin{array}{l}\text { Deactivate cruise } \\
\text { by pressing the } \\
\text { cruise control } \\
\text { switch }\end{array}$ \\
\hline $\begin{array}{l}\text { Cruise } \\
\text { control }\end{array}$ & $\begin{array}{l}\text { Vehicle } \\
\text { speed sensor } \\
\text { gives lower } \\
\text { speed } \\
\text { readings } \\
\text { than normal } \\
\end{array}$ & $\begin{array}{c}\text { The vehicle } \\
\text { accelerates } \\
\text { more than } \\
\text { desired }\end{array}$ & 3 & 2 & 1 & $\mathrm{QM}$ & $\begin{array}{l}\text { Speed sensor } \\
\text { mechanical } \\
\text { failure or } \\
\text { electrical } \\
\text { failure }\end{array}$ & $\begin{array}{c}\text { Avoid } \\
\text { unintended } \\
\text { accelerating } \\
\text { torque }\end{array}$ & $\begin{array}{l}\text { Cancel Cruise } \\
\text { Control }\end{array}$ \\
\hline Driver & $\begin{array}{l}\text { Pedal Misap- } \\
\text { plication }\end{array}$ & $\begin{array}{c}\text { Vehicle } \\
\text { accelerates } \\
\text { when } \\
\text { braking is } \\
\text { intended }\end{array}$ & 3 & 4 & 3 & $\mathrm{D}$ & $\begin{array}{c}\text { Driver } \\
\text { mistake. } \\
\text { Poor pedal } \\
\text { design and } \\
\text { positioning }\end{array}$ & $\begin{array}{c}\text { Avoid } \\
\text { unintended } \\
\text { accelerating } \\
\text { torque } \\
\text { request }\end{array}$ & $\begin{array}{c}\text { The } \\
\text { manufacturer } \\
\text { should improve } \\
\text { the pedal design }\end{array}$ \\
\hline
\end{tabular}

Table 2: Hazard analysis and risk assessment for torque security in electric vehicles 


\subsection{Plant and Fault Modeling}

Although the ASIL associated with each hazard is determined in terms of the three factors discussed in Section 2.2, the way to determine the numerical values of its impact factors is rather subjective. This paper proposes to use quantitative methods by using explicit models that provide justification for the values of $\mathrm{S}$ and $\mathrm{C}$, and therefore help to define ASILs for the considered hazards and make it easier to set functional safety goals. This can be done by modeling the plant and faults so as to conduct quantitative analyses of the fault effects on the overall system using a mathematical model of the system and the associated fault behaviors to evaluate the severity and controllability level of each considered hazard. A detailed model of an electric vehicle powertrain is developed in [25], where the models are based on the experimentally validated models from the EcoCAR2 vehicle, a plug-in hybrid electric vehicle developed at the Ohio State University Center for Automotive Research (OSU CAR). The models are developed such that faults can be easily injected at the component level and their effect on the overall vehicle can be simulated to understand whether they could potentially lead to safety problems.

Zhang et al. [31] investigated the main factors that could contribute to torque functional safety problems by fault modeling analysis. In [31], the authors carried out fault modeling and simulation for the following faults: accelerator pedal stiction fault, brake pedal stiction fault, accelerator pedal sensor fault and cruise control fault such as brake switch fault. As an example of a faulty scenario, one can consider the case where the accelerator gets stuck at a value of $20 \%$ when the driver is releasing the accelerator pedal to stop 
at a traffic light. This is a critical fault since the driver is not able to reduce the accelerating torque beyond this level and the vehicle will continue to accelerate even when deceleration is desired.

To determine the severity level of this type of fault, we simulate the effect of the fault on the vehicle without any control action involved. The result of this open loop simulation is shown in Fig. 4. It should be noticed that many of the nowaday's vehicle has been equipped with an "Brake Override System", where the controller dismisses the accelerator pedal position signal when it receives nonzero signals both in the accelerator pedal and brake pedal. In this paper, for simplicity of comparison, we assume that in the faulty case without any control, the brake override system is not enabled. As can be seen from Fig. 4b, the velocity in the faulty case exceeds the healthy case by up to $22 \mathrm{~km} / \mathrm{h}$. According to ISO26262-3 Table B.1, a fault that results in velocity change between $20 \mathrm{~km} / \mathrm{h}$ and $40 \mathrm{~km} / \mathrm{h}$ could result in severe and possible fatal front/rear collisions and is recommended by ISO26262 to be assigned severity class S2. It should be noted that if the pedal is stuck at a higher level or the vehicle is operating at higher speed and/or high deceleration, the severity level should be classified as S3. Moreover, Fig. $4 \mathrm{~d}$ depicts the comparison of distance traveled between the healthy and the faulty case. Assume that in the healthy case, the vehicle is maintaining a safe distance with the vehicle ahead, then in Fig. 4d, the difference between the black line and the blue line denotes the minimum distance the front/rear vehicle should maintain under at each time instant based on the well known two second rule [32]. As can be seen, under pedal stiction fault, the driver is no longer able to maintain distance between the current vehicle and the 
vehicle ahead, resulting in possible collision with the vehicle ahead and lifethreatening harm to humans.

As to exposure level, since this event involves the operation of the accelerator pedal, which occurs almost anytime during driving, thus it should be assigned to the highest exposure class E4.
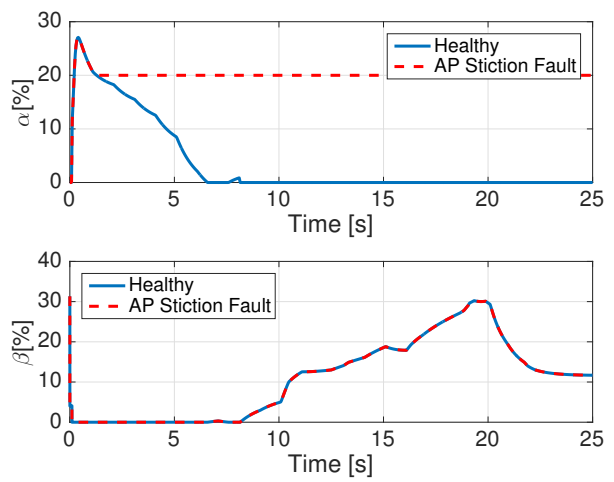

(a) Accelerator and brake pedal position

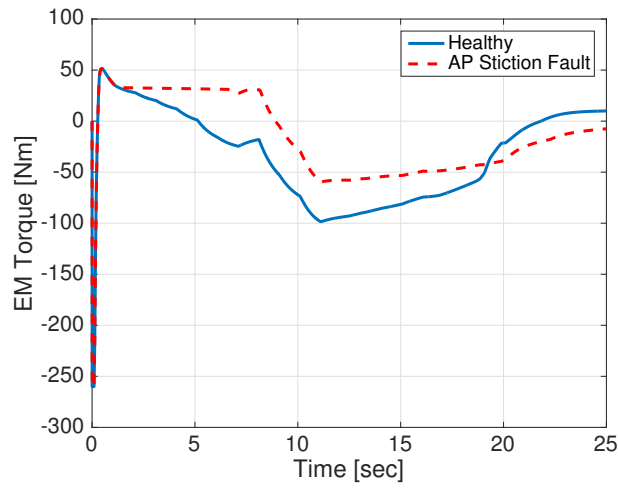

(c) Electric machine torque
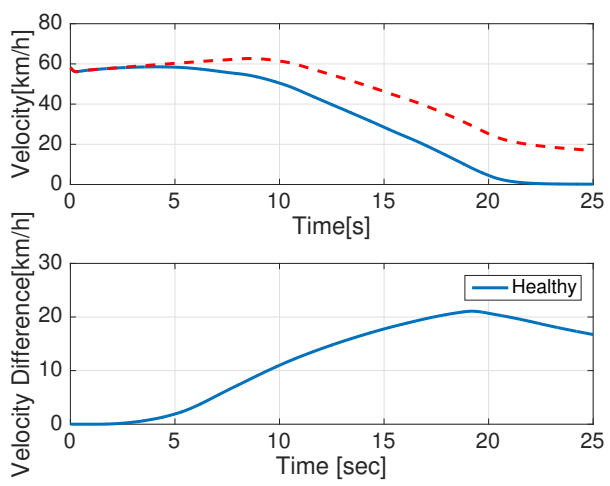

(b) Vehicle speed

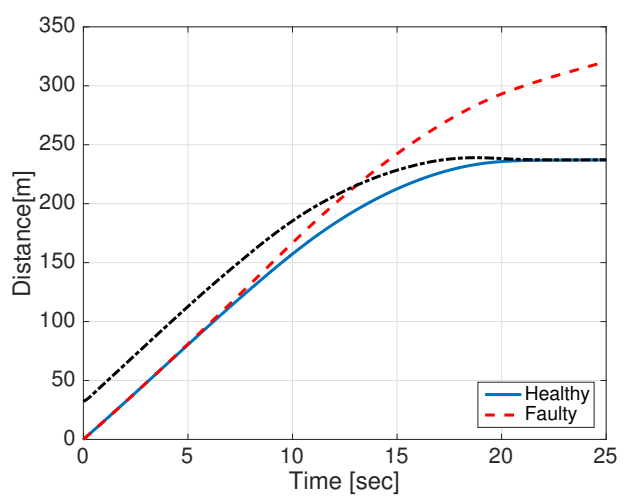

(d) Traveled distance

Figure 4: Simulation results under accelerator pedal stiction fault at $20 \%$

To test the controllability level of this type of fault, we include driver control in the simulation. A detailed description of the vehicle and driver models are presented in [31], where an average driver is modeled as a proportional 
controller responsive to the difference between the desired vehicle speed and the actual speed, taking into account a response delay [33, 34]. The results of this simulation are shown in Fig. 5. As can be seen from $5 \mathrm{a}$ and Fig. 5b, under this kind of fault, the vehicle continues to accelerate until the driver realizes the fault and depresses the brake pedal with greater force to compensate for the effect of this fault. However, the driver may still fail to bring the vehicle to a complete stop in the desired period of time $(25 \mathrm{~s})$. As can be seen from Fig. 5d, with driver control, the distance difference between the faulty and healthy case is notably shortened, compared with Fig. 4d, Nevertheless, the intersection between the red dash line and black dot dash line suggests that the driver still fails to maintain the distance between front and rear vehicle, resulting in possible collisions. Moreover, since aggressive braking is undesirable, both because of brake system wear and because it can have an undesirable effect on vehicle stability, we conclude that this type of fault is very difficult to control and assign the fault with the controllability class C3. In this case, the supervisory controller should assist the driver in bringing the vehicle speed down by reducing the torque request. Later in this paper, we show how a diagnostic and fault mitigation function could compensate the fault effect faster than a typical driver in bringing the vehicle to a safe state.

In conclusion, the process of plant and fault modeling provides the ability to quantitatively assess the severity and controllability levels in the HARA table shown in Table. 2. Based on the results of the fault simulation, we complete the table with more physically justified estimates of severity and controllability levels, and with the resulting ASILs. 

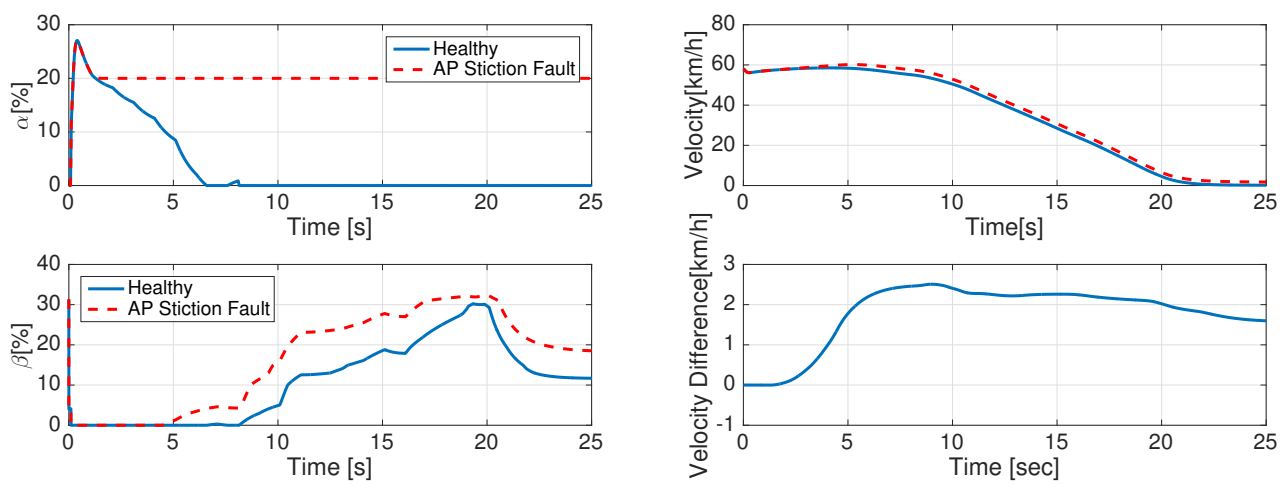

(a) Accelerator and brake pedal position

(b) Vehicle speed

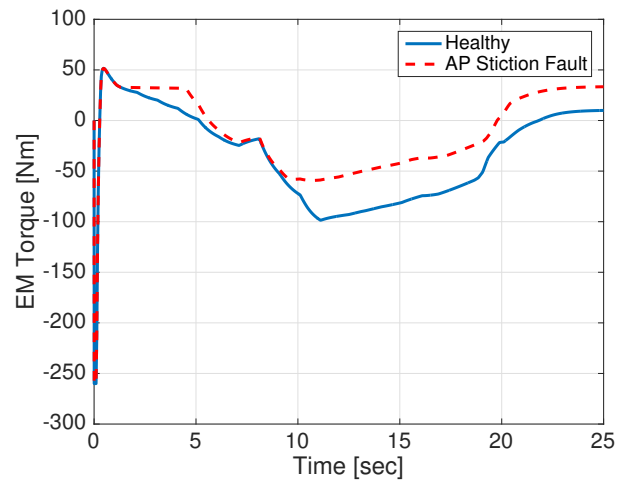

(c) Electric machine torque

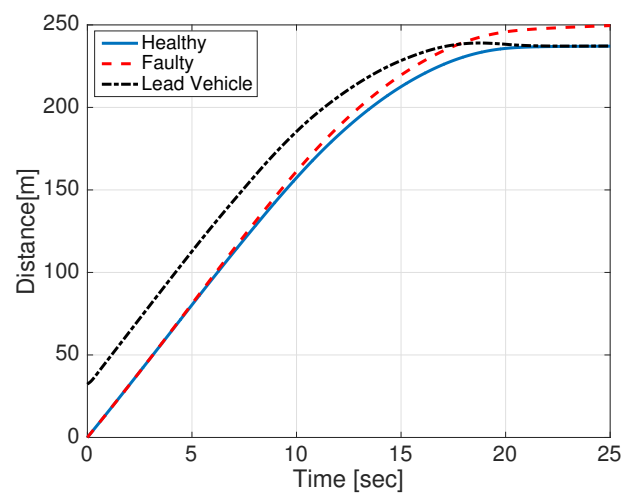

(d) Traveled distance

Figure 5: Simulation results under accelerator pedal stiction fault at 20\%

\subsection{Functional Safety Implementation by Model Based Diagnosis and Fault Tolerant Control}

As part of the ISO26262 standard, a functional safety concept should be implemented by defining the functional safety and technical safety requirements to accomplish safety goals and allocate them to the preliminary architectural elements of the item or to external risk reduction measures [1]. According to ISO26262, while deriving the functional safety requirements, a warning and degradation concept shall be specified in terms of technical 
functions, for example the system can switch to a safe state by fault detection and fault mitigation [1]. This paper proposes to allocate the safety requirements to the diagnostic and fault tolerant control system, i.e., for each of the component hazards, the diagnostic system should detect and identify a fault in an acceptable interval of time, and then the corresponding remedial actions will be taken into effect through fault tolerant control to prevent further damage to the vehicle.

A model-based diagnostic and fault tolerant control system is shown in Fig. 6, where, in the FDI process, a set of residuals are generated by comparing the plant outputs with the estimated outputs from various models, and then the diagnostic decision is made through residual evaluation. The diagnostic system indicates the occurrence of a fault or multiple faults and sends the information to a fault tolerant controller to ensure the appropriate fault mitigation strategies.

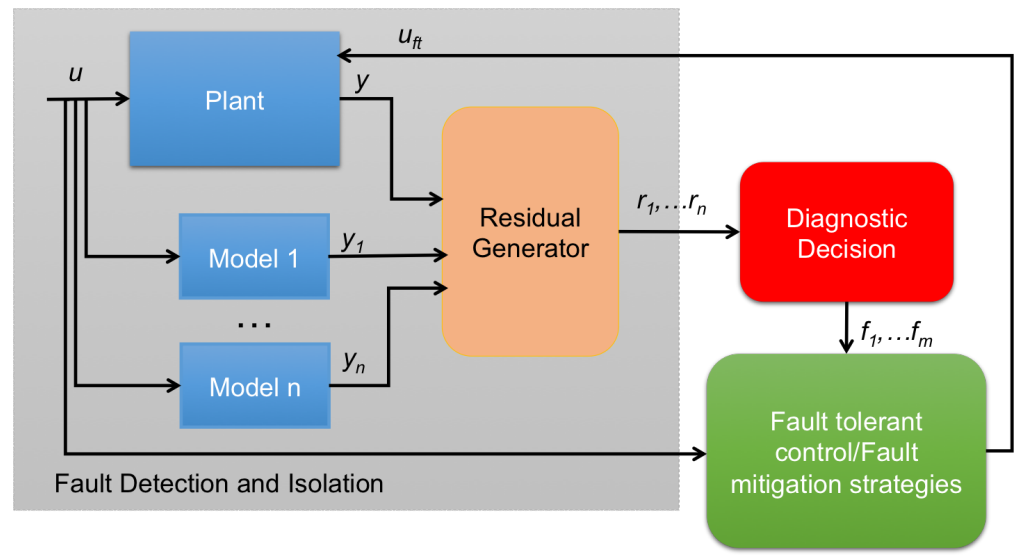

Figure 6: Model based fault diagnostic and fault tolerant control system 


\section{A Safety Case by Model-Based Diagnosis and Fault Tolerant Control - Pedal-by-Wire System Torque Functional Safety}

In a 1989 report published by the U.S. National Highway Traffic Safety Administration (NHTSA), several factors that could potentially lead to sudden unintended acceleration (SUA) incidents were identified and evaluated. According to more recent studies [35, 36] [37], SUA in a conventional ve-

hicle can be caused by the following factors: 1) pedal misapplication; 2) accelerator pedal entrapment or pedal stiction; 3) electronic throttle control problems; 4) cruise control problems and 5) brake system malfunctions. The methodology introduced in this paper is exemplified using a case study based on a critical fault: pedal mechanical stiction fault.

\subsection{Functional safety requirements}

In the concept phase defined by ISO26262, a safety goal sets the top level safety requirements with which the vehicle must conform during its entire safety lifecycle. According to the HARA results in Table 2, the safey goal associated with pedal stiction faults is assigned an ASIL level of C. To achieve this goal, it must be shown that the vehicle is safe in the event of such fault by adopting risk mitigation mechanisms that meet ASIL C requirements.

As has been discussed, this paper uses fault modeling analysis to quantify a safety goal. For subsequent analysis, the same scenario shown in Fig. 5 is considered, which presents a general case where a vehicle stops at a traffic light. Considering the possibility of collision, the safety goal in this case is to ensure that the vehicle acceleration does not exceed the value corresponding to the healthy operation by more than $0.2 \mathrm{~m} / \mathrm{s}^{2}$. Fig. 7 
presents the acceleration difference between the faulty case and the healthy case with driver control. It shows that, in the presence of an accelerator pedal stiction fault, the acceleration bound is exceeded.

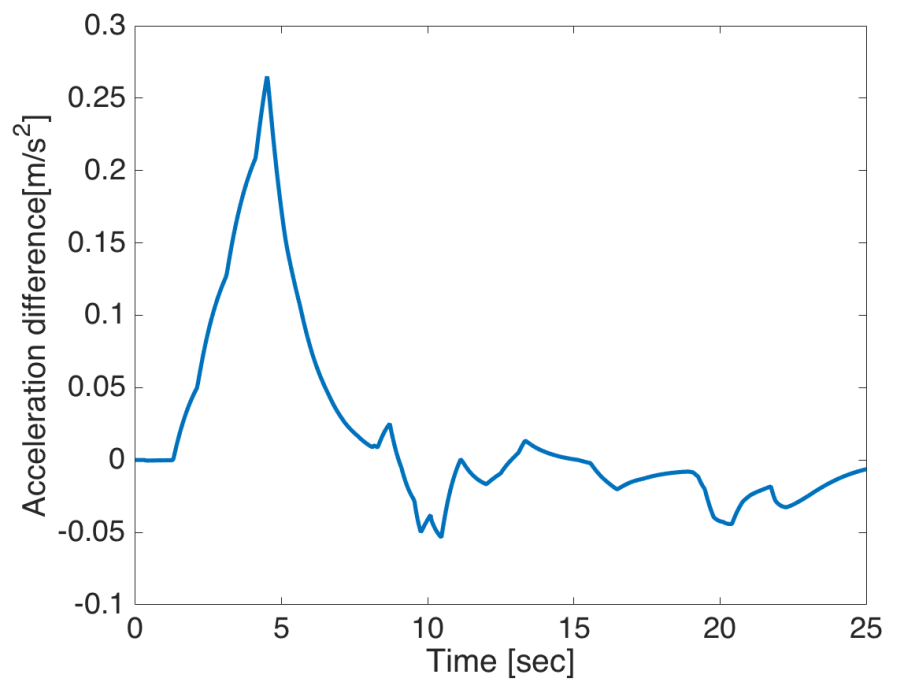

Figure 7: Acceleration difference between faulty and healthy cases

As has been discussed, the function of FDI and FTC is to mitigate the effect of faults before the driver takes remedial actions. To set more specific safety requirements related to FDI, which are considered as part of technical safety requirements by ISO26262, one can consider the vehicle dynamics equation during a non-braking process expressed in Eq. (1) through Eq. (3), where, $M$ is the mass of the vehicle, $F_{\text {trac }}$ represents the tractive force delivered at the wheels; $F_{a x l e, \max }$ stands for the maximum torque at the axle; $F_{L}$ is the road load, which is a function of vehicle speed and road conditions such as friction and grade; $T_{m}$ is the electric motor torque, $\gamma_{w}$ represents the radius of the wheels, and $R_{G b}$ stands for the gearbox ratio. The study presented in this paper is based on parame- 
ters from the rear powertrain (electric powertrain) of the EcoCAR2 vehicle: $M=2000 \mathrm{~kg}, T_{a x l e, \max }=2070 \mathrm{Nm}, \gamma_{w}=0.35 \mathrm{~m}, \eta_{G b}=8.28$.

$$
\begin{aligned}
& M \frac{d V_{v e h}}{d t}=F_{\text {trac }}-F_{L} \\
& F_{\text {trac }}=\frac{\alpha}{100} * F_{a x l e, \max } \\
& T_{m}=\frac{F_{t r a c} \gamma_{w}}{\eta_{G b}}
\end{aligned}
$$

Eq. (2) presents the relationship between tractive force and accelerator pedal position. In this paper, we consider only EV mode operation of the powertrain, where the tractive torque only comes from the electric machine. The model allows us to calculate the torque from acceleration, and therefore the pedal position, making it possible to set bounds for electric machine torque and pedal position that are consistent with the bound set in the safety goal for the maximum allowable deviation in acceleration relative to the normal operation. For example, Fig. 7 shows that because of the driver delay, even in the presence of driver control, the safety goal is violated. To meet the safety goal, we take the steps of diagnosing the pedal stiction fault within a window of time that is shorter than the response time of an average driver. [33, 34]. After the fault is detected, a FTC algorithm is then implemented, which rapidly reduces the pedal position signal to the control unit to zero. The reduction rate is fast enough such that safety goal is met without sacrificing vehicle performance. The details of the FDI and FTC algorithms are shown in Section 3.2. 


\subsection{Structural FDI and Fault Tolerant Control for Torque Functional Safety in Electrified Vehicles}

In this section, we use the structural analysis approach to analyze the detectability and isolability properties of various faults that can lead to torque functional safety problems and design various diagnostic tests to detect and isolate those faults. This section also shows, by integrating fault detection and isolation with fault tolerant control actions, the vehicle is capable of actively avoiding unintended acceleration and fulfill the safety goal with less dependence on the driver.

\subsubsection{Structural Analysis for FDI}

I. Electric Vehicle Mathematical and Structural Model. In structural analysis, a structural model is used to represent the relationship between the equations of a model and the associated variables.

Definition 1. (Structural Model) 10] Given a set of model equations $E$ and the associated variables $V$, a structural model is represented by an incidence matrix whose elements $a_{i j}$ are defined as:

$$
a_{i j}= \begin{cases}1 & \text { if } v_{j} \text { appears in } e_{i}, \text { where } v_{j} \in V, e_{i} \in E \\ 0 & \text { if otherwise }\end{cases}
$$

In a structural model, two sets of variables are defined separately: the set of unknown variables are defined as all the dynamic and algebraic states, while the set of known variables are defined as known inputs such as control input commands and direct outputs from the sensor measurements. The aim of structural analysis for FDI is to find analytic redundant relations by 
eliminating the unknown variables from the known ones.

To perform structural analysis for electrified powertrains, we use a simplified mathematical model for an electric vehicle equipped with a PMSM drive system, described in Appendix A. The models are developed based on the experimentally validated models of the EcoCAR2 vehicle, where equation $e_{1}$ describes the behavior of the accelerator pedal, $\alpha_{r e f}$ is the reference accelerator pedal position and $f_{\alpha}$ represents a fault in the accelerator pedal. $e_{2}$ through $e_{5}$ illustrate the torque calculation based on the driver commands(or brake pedal position $\alpha$ and $\beta$ ). $T_{\text {eref }}$ is the total torque reference from the electric machine, evaluated at the wheels, that is, the sum of the accelerating torque reference $T_{a c c}$ and the regenerative braking torque referene $T_{b r k . e m}$. $T_{a c c}$ is linear function of the measured accelerator pedal position and the maximum capable torque delivered at the axle $T_{\text {max,axle }}$, while $T_{b r k, e m}$ is a nonlinear function of the measured brake pedal position and vehicle speed. When needed, there is friction brake $\left(T_{b r k, f r}\right)$ that is a function of the brake pedal position acting on the wheels in addition to the EM brake. If we assume that the driver never presses the accelerator pedal and brake pedal together, then $e_{6}$ represents the relationship between the accelerator pedal position and brake pedal position. $e_{7}$ describe the actual electric machine torque, considering the accelerating torque and regenerative braking torque limits $\left(T_{e m, \max }\right.$ and $\left.T_{e m, \min }\right) . e_{8}$ is total force delievered at the wheels. It is assumed that the EM is rigidly connected to the axle, and a single speed gearbox, whose speed reduction ratio is $\eta_{g b}$, is placed between the EM and the rear axle. $e_{9}$ stands for the longitudinal vehicle dynamics, given the total delievered force, and road load force $F_{L} \cdot e_{10}$ through $e_{13}$ are the sensor equa- 
tions describing the measurements of the accelerator pedal and brake pedal $\left(y_{\alpha_{1}}, y_{\alpha_{2}}, y_{\beta_{1}}, y_{\beta_{2}}\right)$. One can assume that each pedal is equipped with two independent potentiometers measuring its travel, which is a comonly used sensor architecture in the automotive industry, as described by [38, 39].

In this paper, the following faults are considered: 1) accelerator pedal stiction fault; 2) faults in either of the two accelerator pedal sensors, namely, APPS1 and APPS2; and 3) two brake pedal sensor faults in BPPS1 and BPPS2. It is also assumed that only one fault occurs at a time. Based on its mathematical model, the structural model of the electric vehicle is developed as shown in Fig. 8, where variables in the $x$ axis correspond to the variables in Eq. A.1]: alpha $=\mathrm{aph}=\alpha$, beta $=\beta$, alphar $=\alpha_{\text {ref }}$, Tbrkm $=$ $T_{b r k, e m}, \operatorname{Tbrkfr}=T_{b r k, f r}, \operatorname{Tmax}=T_{m a x, a x l e}, \operatorname{Tmaxm}=T_{e m, \max }$, Tminm $=T_{e m, \min }$.

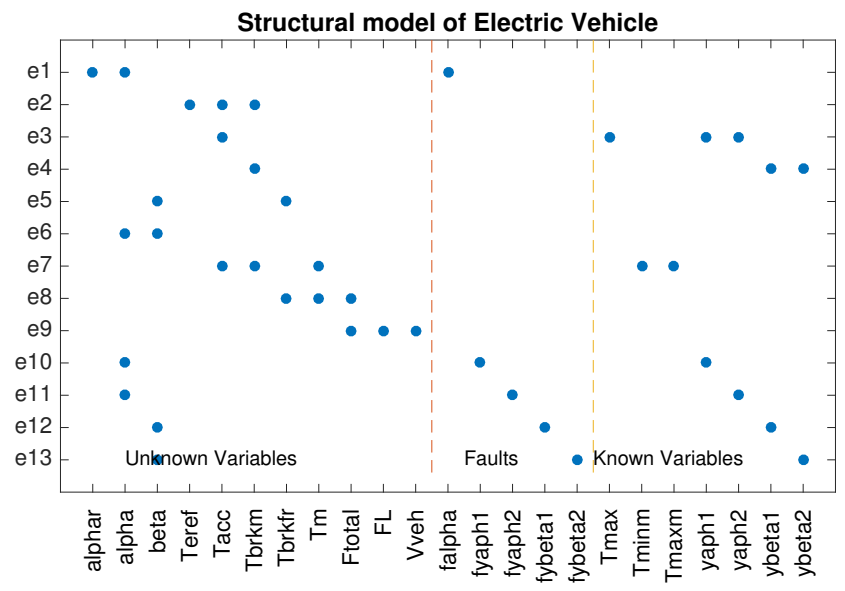

Figure 8: Structural model of electric vehicle 
II. Redundancy of the EV Model for Fault Detection. Model based diagnosis relies on a model's analytic redundancy [40], which can be found by peforming a Dulmage-Mendelsohn (DM) decomposition on the incidence matrix that represent the structural model. [41, 14]. Through DM-decomposition, a structural model can be decomposed into three parts, as shown in Fig. 9 .

- Structurally under-determined part $M^{-}$, where there are fewer equations than unknowns;

- Structurally just-determined part $M^{0}$, where there are equal number of equations and unknowns;

- Structurally over-determined part $M^{+}$, where there are more equations than unknowns; this is the part where the analytic redundancy of the model resides.

According to reference [14], a fault $f_{i}$ can be detected if the equation it affects lies in the structurally over-determined part, i.e. $e_{f_{i}} \in M^{+}$

The DM decomposition of the EV structural model is shown in Fig. 10. From the decomposition graph, it can be seen that the accelerator fault is not detectable since the equation it affects $\left(e_{1}\right)$ lies in the structurally justdetermined part. This is due to the fact that, for a pedal-by-wire system, the supervisory controller receives pedal information only from the pedal sensor readings. In real driving, the controller does not have the information of the actual accelerator position request from the driver. Therefore, when it receives the wrong information, it is impossible to tell whether it is due to the pedal error, or it is due the driver intention. 


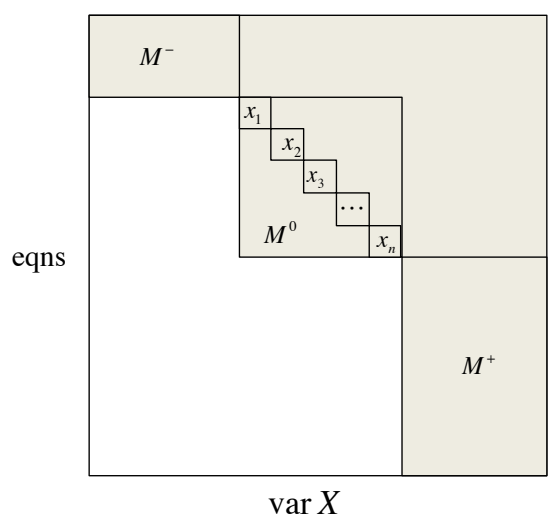

Figure 9: Dulmage-Mendelsohn decomposition of a model

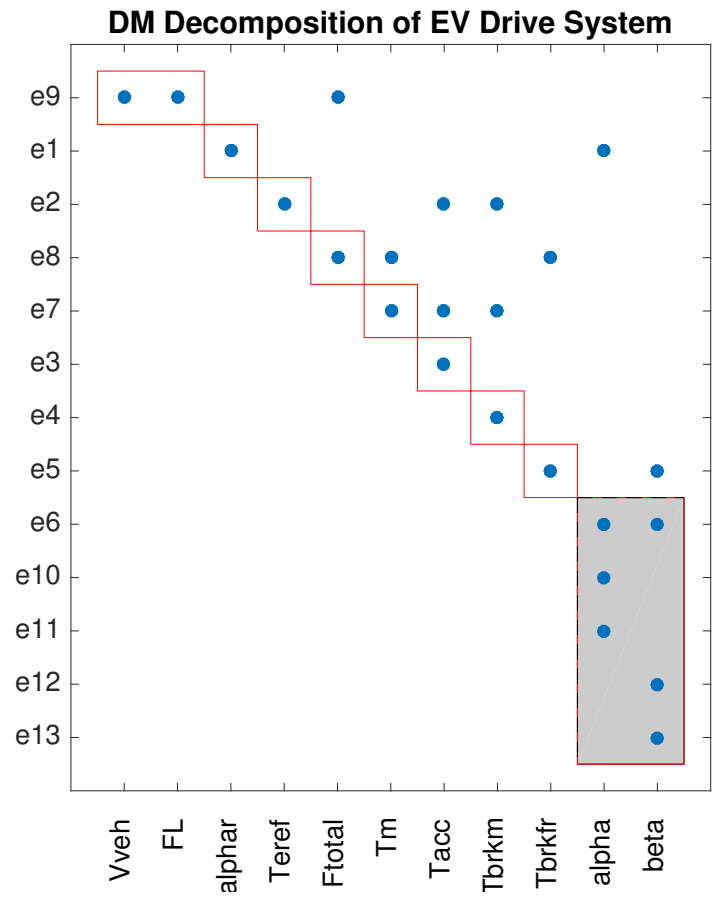

Figure 10: DM-Decomposition of electric vehicle structural model

However, one can consider the case when the pedal gets stuck at partially depressed position, as has been discussed in Section 3.1. To detect the pedal stiction fault, a fault model is added to the EV structural model based on the fact that if the accelerator pedal is assumed to be stuck at a constant 
level, its derivative is zero. Therefore, $e_{1}$ is replaced with Eq. (5), and a new model is developed in Appendix B.

$$
e_{1}: \dot{\alpha}=f_{f_{s t k}} \quad e_{2}: \dot{\alpha}=\frac{d \alpha}{d t}
$$

where, $f_{f_{s t k}}$ represents a fault in our assumption. If $f_{f_{s t k}}=0$, it means our assumption is correct and accelerator pedal is actually stuck at a constant level; otherwise our assumption is wrong and the stiction fault has not occurred. It should be noted that during real driving, it is entirely possible that the driver intentionally keeps the accelerator pedal at a relatively constant position, in which case it is difficult to tell whether there is pedal fault or it's the driver intent, which may lead to possible false alarms. In this paper, some delay is introduced in making the diagnostic decision to reduce false alarms, though we make the assumption that the fault occurs when the accelerator pedal is varying adequately fast and the driver is not likely to keep the pedal constant for a long time, which is a reasonable assumption due to the normal variability in road load. One should notice that if the vehicle is in cruise mode, the fact is known to the controller and the logic just described does not apply. Similarly, the algorithm is inactive when the vehicle is stopped, since in both cases, the pedal is not in use and pedal position derivative is always zero. Another case that is not covered by this algorithm is the circumstance where $\alpha$ gets stuck at its maximum position, which is difficult to be distinguished from the case when driver intentionally keeps the pedal at its maximum position for some time such as when it tows a trailer. This requires a more sophisticated diagnostic algorithm that will be studied in our future work. 


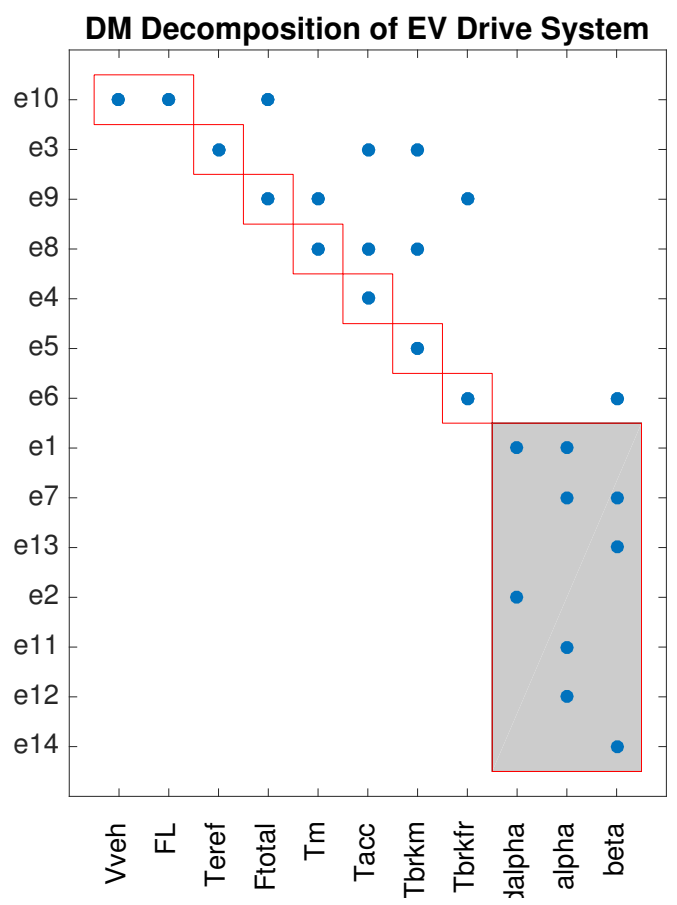

Figure 11: DM-Decomposition of the EV structural model with pedal fault model

Adding these equations to the mathematical model, it is found that the pedal stiction fault becomes detectable as it lies in the structural overdetermined part, as shown in Fig. 11.

III. Diagnostic Test Selection for Torque Functional Safety.

Minimum Structurally Overdetermined (MSO) Sets A diagnosis test can be designed by utilizing Minimal Structurally Overdetermined sets (MSO sets) in which there is one more equation than unknowns, i.e, with redundancy of one [15]. MSO sets are designed to use as few equations as possible, while redundancy is still maintained in order to detect specific faults. The use of MSO sets decomposes a complex system into smaller, simpler sub-models, from which it is more efficient to design residuals and 


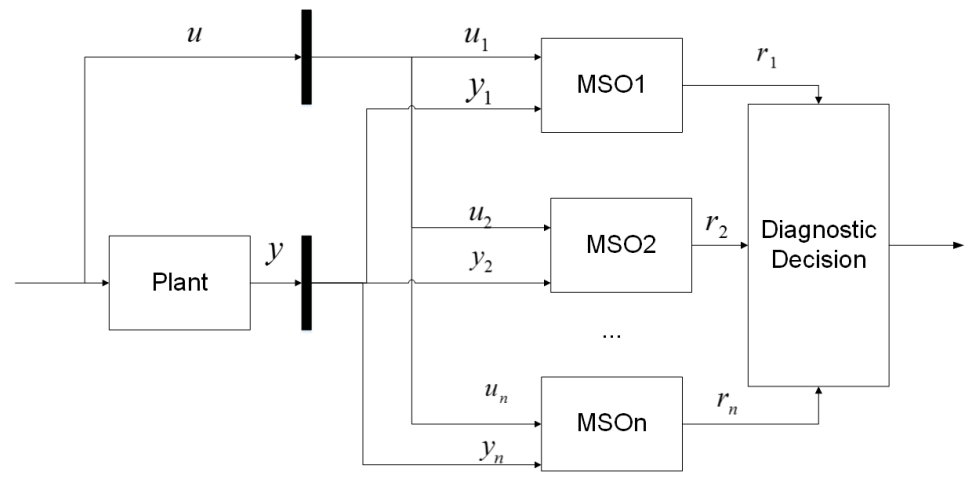

Figure 12: Diagnosis through Minimal Structurally Overdetermined sets

apply specific diagnostic algorithms. For each MSO set, one consistency relation to form a residual can be found by eliminating the unknown variables sequentially from its equations except for one equation that is selected to generate a residual. The residuals found in this way are called sequential residual generators [12, 11, 22]. Krysander et al. [15] discuss an efficient algorithm to find all MSO sets that provide us with all the possible options of diagnostic tests for the considered faults. Whether one chooses to use a MSO and how many MSOs to use, depends on the requirements of the diagnostic problem and specifics of the system [17, 19, 21]. The diagnostic process using MSO sets is illustrated in Fig. 12, where $u_{1}, u_{2}, \cdots, u_{n}$ are subsets of system inputs, $y_{1}, y_{2}, \cdots, y_{n}$ are subsets of measurements. Isolation of various faults are achieved by comparing the outputs of the different MSO sets.

Based on the EV structural model, a number of MSO sets can be found to construct diagnostic tests that can isolate all the faults considered in the model. The diagnostic tests are chosen so that they are affected by different sets of faults, and therefore result in unique diagnosis of each fault. Using the algorithm introduced in [15, the following six MSO sets can be found to 
construct diagnostic tests. And for each MSO, one can obtain a residual by eliminating the unknown variables from the known ones.

MSO1: MSO2: MSO3:
$e_{1}: \dot{\alpha}=f_{f_{s t k}}$
$e_{1}: \dot{\alpha}=f_{f_{s t k}}$
$e_{11}: y_{\alpha_{1}}=\alpha+f_{y_{\alpha_{1}}}$
$e_{2}: \dot{\alpha}=\frac{d \alpha}{d t}$
$e_{2}: \dot{\alpha}=\frac{d \alpha}{d t}$
$e_{11}: y_{\alpha_{1}}=\alpha+f_{y_{\alpha_{1}}}$
$e_{12}: y_{\alpha_{2}}=\alpha+f_{y_{\alpha_{2}}}$
$e_{12}: y_{\alpha_{2}}=\alpha+f_{y_{\alpha_{2}}}$
$\mathbf{R}_{1}=\dot{\mathbf{y}}_{\alpha_{1}}$
$\mathbf{R}_{2}=\dot{\mathbf{y}}_{\alpha_{2}}$
$\mathbf{R}_{\mathbf{3}}=\mathbf{y}_{\alpha_{\mathbf{1}}}-\mathbf{y}_{\alpha_{\mathbf{2}}}$

MSO4 :

MSO5:

$$
\begin{aligned}
& e_{13}: y_{\beta_{1}}=\beta+f_{y_{\beta_{1}}} \\
& e_{14}: y_{\beta_{2}}=\beta+f_{y_{\beta_{2}}} \\
& \mathbf{R}_{\mathbf{4}}=\mathbf{y}_{\beta_{\mathbf{1}}}-\mathbf{y}_{\beta_{\mathbf{2}}}
\end{aligned}
$$

$e_{7}: \alpha \beta=0$



$e_{11}: y_{\alpha_{1}}=\alpha+f_{y_{\alpha_{1}}}$

$e_{13}: y_{\beta_{1}}=\beta+f_{y_{\beta_{1}}}$

$\mathbf{R}_{\mathbf{5}}=\mathbf{y}_{\alpha_{\mathbf{1}}} \cdot \mathbf{y}_{\beta_{\mathbf{1}}}$

$e_{7}: \alpha \beta=0$

$e_{12}: y_{\alpha_{2}}=\alpha+f_{y_{\alpha_{2}}}$

$e_{13}: y_{\beta_{1}}=\beta+f_{y_{\beta_{1}}}$

$\mathbf{R}_{\mathbf{6}}=\mathbf{y}_{\alpha_{\mathbf{2}}} \cdot \mathbf{y}_{\beta_{1}}$

MSO7:

MSO8:

$$
\begin{array}{ll}
e_{7}: \alpha \beta=0 & e_{7}: \alpha \beta=0 \\
e_{11}: y_{\alpha_{1}}=\alpha+f_{y_{\alpha_{1}}} & e_{12}: y_{\alpha_{2}}=\alpha+f_{y_{\alpha_{2}}} \\
e_{14}: y_{\beta_{2}}=\beta+f_{y_{\beta_{2}}} & e_{14}: y_{\beta_{2}}=\beta+f_{y_{\beta_{2}}} \\
\mathbf{R}_{\mathbf{7}}=\mathbf{y}_{\alpha_{\mathbf{1}}} \cdot \mathbf{y}_{\beta_{\mathbf{2}}} & \mathbf{R}_{\mathbf{8}}=\mathbf{y}_{\alpha_{\mathbf{2}}} \cdot \mathbf{y}_{\beta_{\mathbf{2}}}
\end{array}
$$

Table 3: MSO sets for FDI of the considered faults

For example, MSO1 and MSO2 are used to detect and isolate pedal stiction fault, while MSO3 MSO6 are used to detect and isolate pedal position sensor (APPS) faults only. The characteristics of residuals from each MSO set under faults are illustrated in Table 4, where "1" stands for a nonzero residual, while "0" represents a zero residual, and "X" means the residual can be either nonzero or zero. As can be seen, when there is a pedal stiction 
fault, $\dot{y}_{\alpha_{1}}=0, \dot{y}_{\alpha_{2}}=0$, the residual outputs from MSO1 and MSO2 should be zero. However, the zero outputs from MSO1 or MSO2 do not necessarily mean the pedal gets mechanically stuck, since there may be a fault in the accelerator pedal sensor, which is the reason why one needs to add MSO3 to detect an accelerator pedal position sensor fault by detecting a mismatch between the two APPSs.

As it is assumed that the driver never presses the accelerator and brake pedals simultaneously, it is possible to identify which of the accelerator pedal sensors is actually faulty by comparing the outputs of the accelerator pedal sensors and brake pedal sensors. For example, as can be seen from MSO5 and MSO6, or MSO7 and MSO8, when the driver presses the brake pedal, one should expect the accelerator pedal position to be zero. That means, if one sees a nonzero product of $\alpha$ and $\beta$, one of the accelerator pedal sensor failures is likely to occur. Considering the possibility of brake pedal sensor failure, MSO3 $\sim \mathrm{MSO} 8$ are needed to isolate the particular sensor failure. To isolate the particular faulty sensor, the algorithm would depend on the driver depressing the other pedal. To deal with this problem, the controller first detects a APP or BPP sensor fault through MSO3 and MSO4, then the controller warns the driver to press the other pedal so as to isolate the particular sensor fault.

\subsubsection{Fault Tolerant Control Strategies for Torque Functional Safety}

A schematic description of the fault tolerant control strategy is given in Fig. 13, the Fault Mitigation block computes the value of $\alpha_{\text {ovr }}$ by taking as input the measured value of $\alpha$ and the current value of the fault flag $(F F)$. $\alpha_{\text {ovr }}$ is an override value that is summed to the actual value of the accelerator 


\begin{tabular}{c|c|c|c|c|c|c|c|c|c}
\hline & \multirow{2}{*}{ normal } & \multicolumn{2}{|c|}{$f_{f_{s t k}}$} & $\beta=0$ & \multicolumn{2}{c|}{$\beta>0$} & $\alpha=0$ & \multicolumn{2}{c}{$\alpha>0$} \\
\cline { 3 - 10 } & & $\beta=0$ & $\beta>0$ & $f_{y_{\alpha}}$ & $f_{y_{\alpha_{1}}}$ & $f_{y_{\alpha_{2}}}$ & $f_{y_{\beta}}$ & $f_{y_{\beta_{1}}}$ & $f_{y_{\beta_{2}}}$ \\
\hline MSO1 & $\mathrm{X}$ & 0 & 0 & $\mathrm{X}$ & $\mathrm{X}$ & $\mathrm{X}$ & $\mathrm{X}$ & $\mathrm{X}$ & $\mathrm{X}$ \\
\hline MSO2 & $\mathrm{X}$ & 0 & 0 & $\mathrm{X}$ & $\mathrm{X}$ & $\mathrm{X}$ & $\mathrm{X}$ & $\mathrm{X}$ & $\mathrm{X}$ \\
\hline MSO3 & 0 & 0 & 0 & 1 & 1 & 1 & 0 & 0 & 0 \\
\hline MSO4 & 0 & 0 & 0 & 0 & 0 & 0 & 1 & 1 & 1 \\
\hline MSO5 & 0 & 0 & 1 & 0 & 1 & 0 & 0 & 1 & 0 \\
\hline MSO6 & 0 & 0 & 1 & 0 & 0 & 1 & 0 & 1 & 0 \\
\hline MSO7 & 0 & 0 & 1 & 0 & 1 & 0 & 0 & 0 & 1 \\
\hline MSO8 & 0 & 0 & 1 & 0 & 0 & 1 & 0 & 0 & 1 \\
\hline
\end{tabular}

Table 4: Characteristics of fault effects

position, as expressed by Eq. (6), where $T_{s}$ denotes the sampling time.

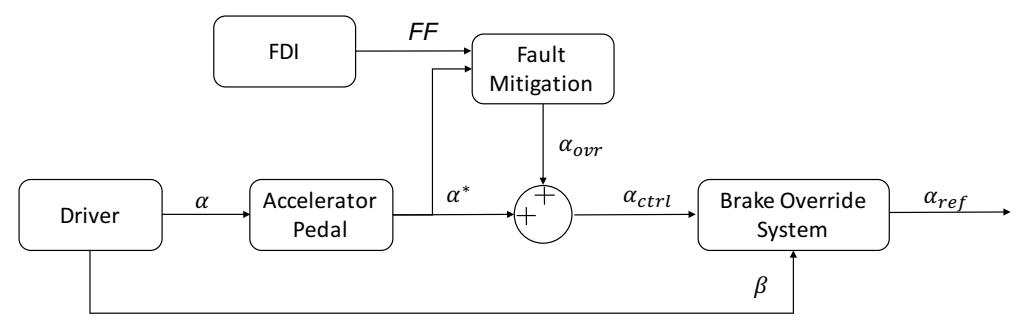

Figure 13: Scheme of the fault tolerant control strategy

$$
\begin{array}{ll}
\alpha_{o v r, 0}=0 & \\
F F_{k}=1: & \alpha_{o v r, k}=\max \left\{-\alpha, \alpha_{o v r, k-1}-\lambda_{1} T_{s}\right\} \\
F F_{k}=0: & \alpha_{o v r, k}=\min \left\{\alpha_{o v r, k-1}+\lambda_{0} T_{s}, 0\right\}
\end{array}
$$

At the beginning, $\alpha_{o v r}=0$ and $\alpha_{c t r l}=\alpha$. When a fault is detected and the fault flag is set high $(F F=1)$, the value of $\alpha_{\text {ovr }}$ will then start decreasing with a slope defined by the parameter $\lambda_{1}>0$. This parameter is set such that the acceleration deviation does not exceed the bound at any time. If the fault flag remains high, $\alpha_{\text {ovr }}$ will reduce from 0 to $-\alpha$, meaning 
that the controlled accelerator pedal position $\alpha_{c t r l}$ will go to zero. On the other hand, if this is a false alarm, as an effect of the reduction of $\alpha_{c t r l}$, the driver would need to depress the accelerator pedal to compensate for the decreased performance, thus making the controller realize that the pedal was not actually stuck, by which time the fault flag will be removed and the value of $\alpha_{\text {ovr }}$ will increase again with a rate defined by the parameter $\lambda_{0}>0$. The value of $\alpha_{\text {ovr }}$ will then increase again from $-\alpha$ to 0 , which means that $\alpha_{c t r l}$ will go from 0 to match again the value of $\alpha$ requested by the driver. This smooth raise of $\alpha_{\text {ovr }}$ is intended to avoid stepwise changes in $\alpha_{c t r l}$ when the fault flag is removed, which may cause a sudden acceleration that can be higher than what the driver expects. The aim is to reduce safety hazards due to the sudden acceleration and to avoid possible drivability issues.

Finally, this FTC algorithm is followed by a "Brake Override System", meaning that, if the driver depresses the brake pedal, $\alpha$ command is immediately reduced to zero. Brake override systems have been applied to many modern vehicles to ensure safety; the FTC technique proposed here has the function of anticipating the driver and reducing $\alpha$ signals before the driver realizes the fault has happened.

\subsubsection{Simulation Results}

This section presents some simulation results to show the effectiveness of the FDI and FTC algorithms for accelerator pedal stiction fault, to avoid unintended acceleration. In this section, the authors used as testbed the EcoCAR2 prototype vehicle. The simulation is done based on experimentally validated EcoCAR2 models and parameters. The considered scenario is the same as the one in Fig. 5 and the results are presented in Fig. 14. 

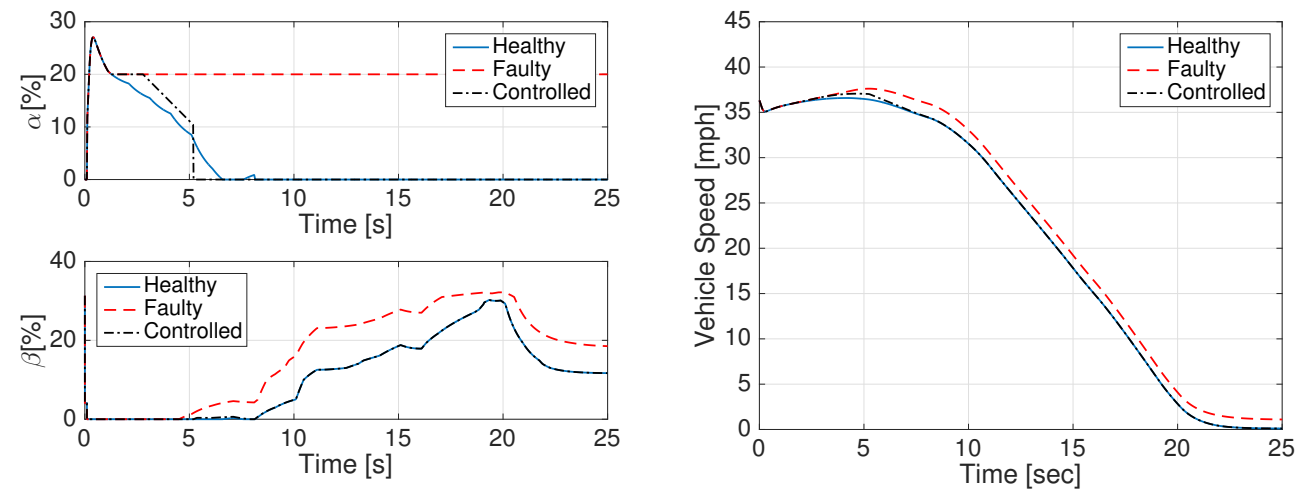

(a) Accelerator and brake pedal position

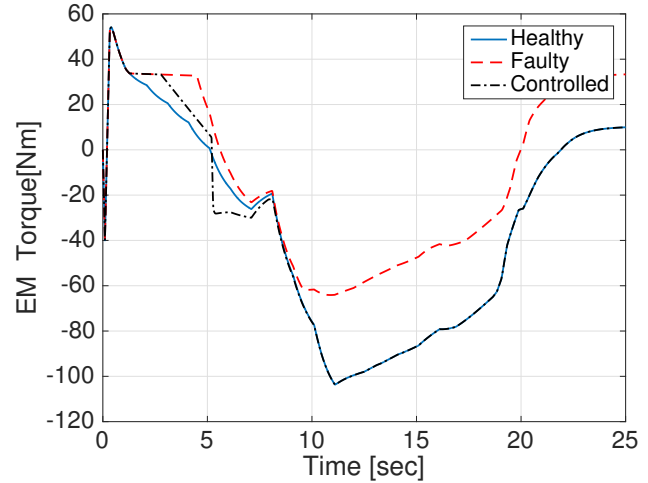

(c) Electric machine torque (b) Vehicle speed

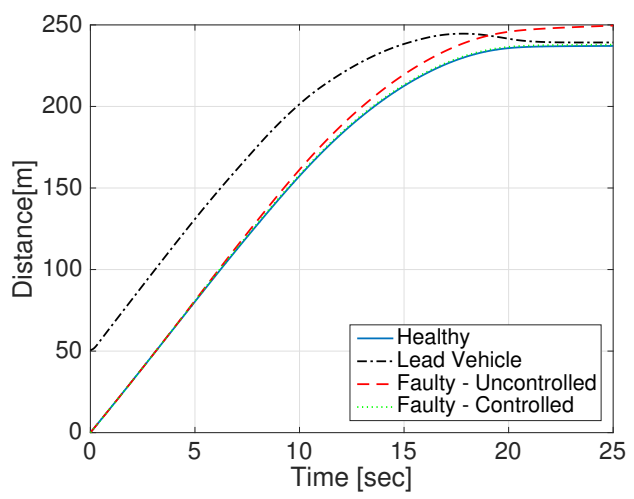

(d) Traveled distance

Figure 14: Simulation results under accelerator pedal stiction fault at $20 \%$ with fault tolerant control

Fig. 14b and Fig. 14d show that the control algorithm helps in mitigating the increase in vehicle speed and traveled distance due to the fault. As can be seen, the vehicle is now able to keep the distance between front/rear vehicle with the help of fault tolerant control and thus avoid collision. As can be seen from Fig. 14a, after the fault is detected, the controlled pedal position is reduced until the driver depresses the brake pedal, by which time it is set to zero immediately due to the effect of the brake override system. 
Fig. 15 shows the residual responses from Table 3. As can be seen from Fig. $15 \mathrm{a}$ and Fig. 15b, the residuals (derivatives of the pedal position) fall into the threshold within $0.05 \mathrm{~s}$. However, the warning system waits $1.5 \mathrm{~s}$ to fire a fault flag in order to avoid false alarms, under the condition that the safety goal is fulfilled.

Finally, the fault flag for accelerator pedal stiction fault is shown in Fig. 16. As can be seen, there is detection delay of $1.6 \mathrm{~s}$.

\subsection{Functional Safety Assessment}

Fig. 17 shows the comparison of deviation in acceleration with and without fault tolerant control. As can be seen, under fault tolerant control, the functional safety goal has been satisfied: the acceleration under accelerator pedal stiction fault never exceeds that in the healthy case by $0.2 \mathrm{~s} / \mathrm{m}^{2}$. The detection delay helps avoid false alarms, while ensuring the acceleration not to exceed the bound at any time.

In conclusion, By introducing fault diagnosis and fault tolerant control, the vehicle is now in safe state.

\section{Conclusion}

This paper presents a model-based approach for defining functional safety requirements, and provides a solution to functional safety problems based on model-based diagnosis and fault tolerant control; the paper also presents a case study on torque functional safety of pedal-by-wire systems in electrified vehicles. According to ISO26262, automotive functional safety requires the definition of safety goals and safety requirements for each of the considered hazards. In the same spirit, this paper defines functional safety requirements 


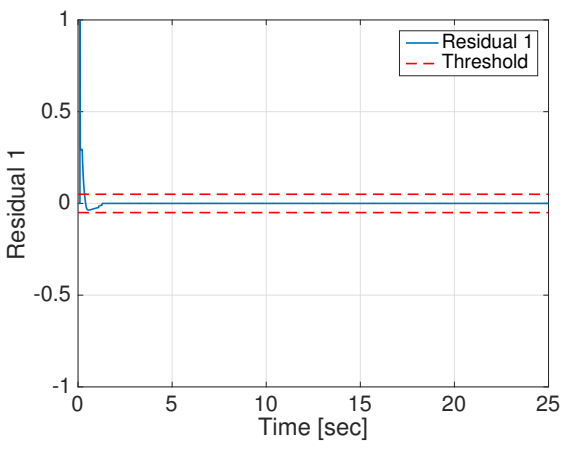

(a) Residual 1

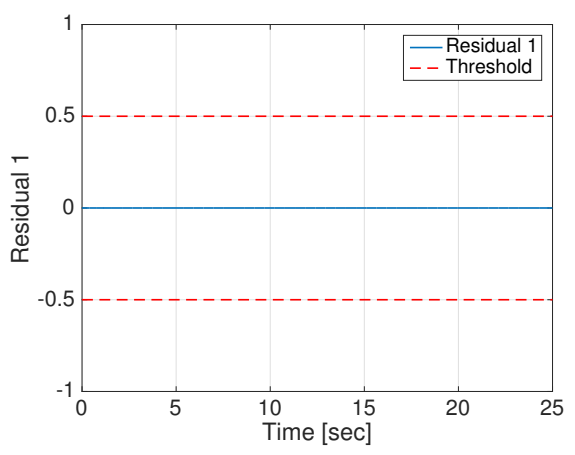

(c) Residual 3

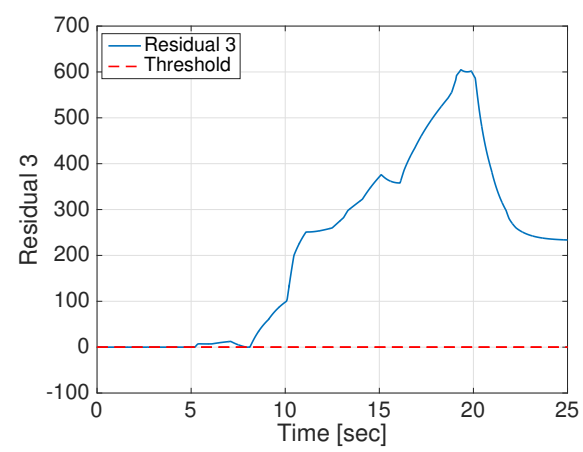

(e) Residual 5

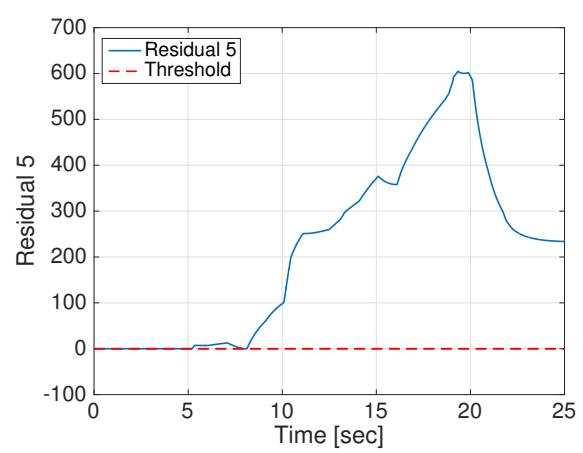

(g) Residual 7

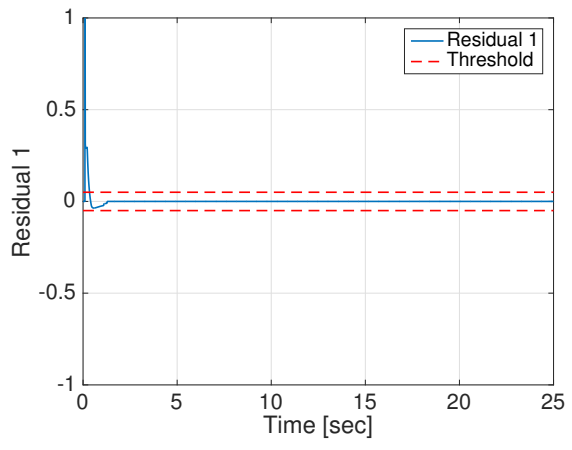

(b) Residual 2

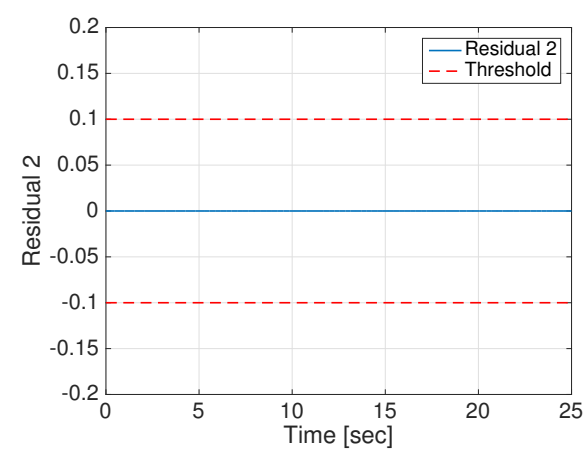

(d) Residual 4

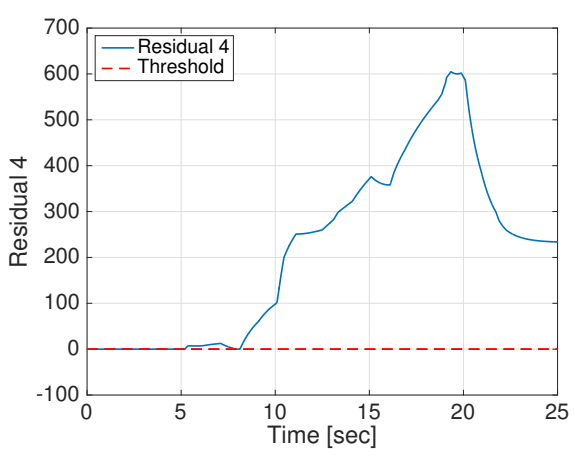

(f) Residual 6

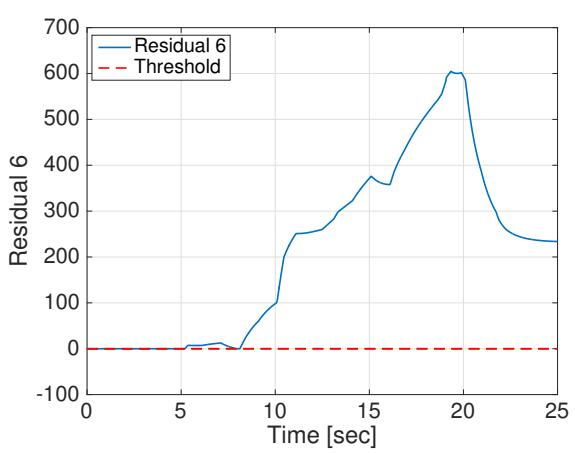

(h) Residual 8

Figure 15: Residuals from the MSO sets 


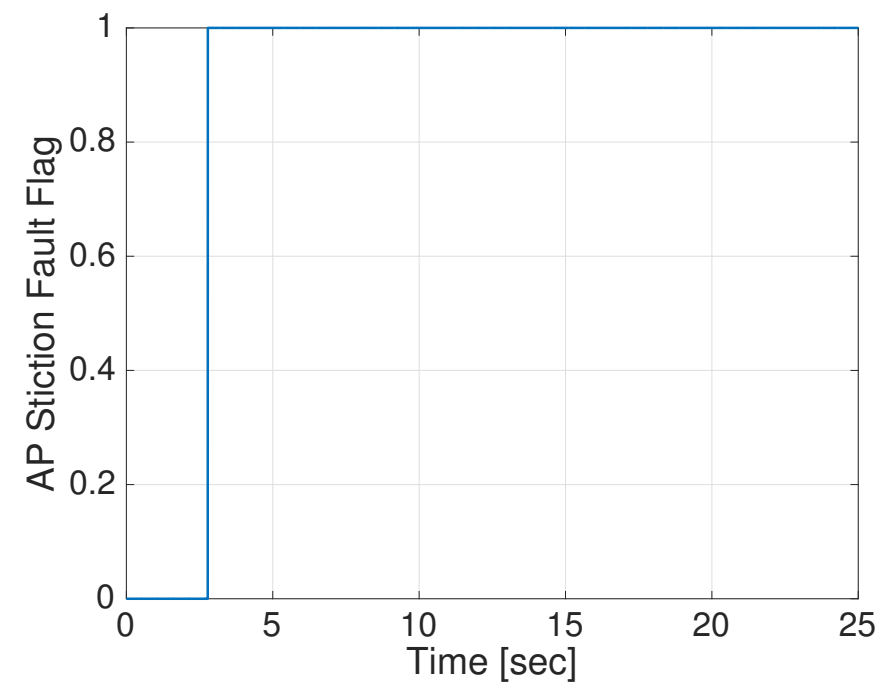

Figure 16: Pedal stiction fault flag

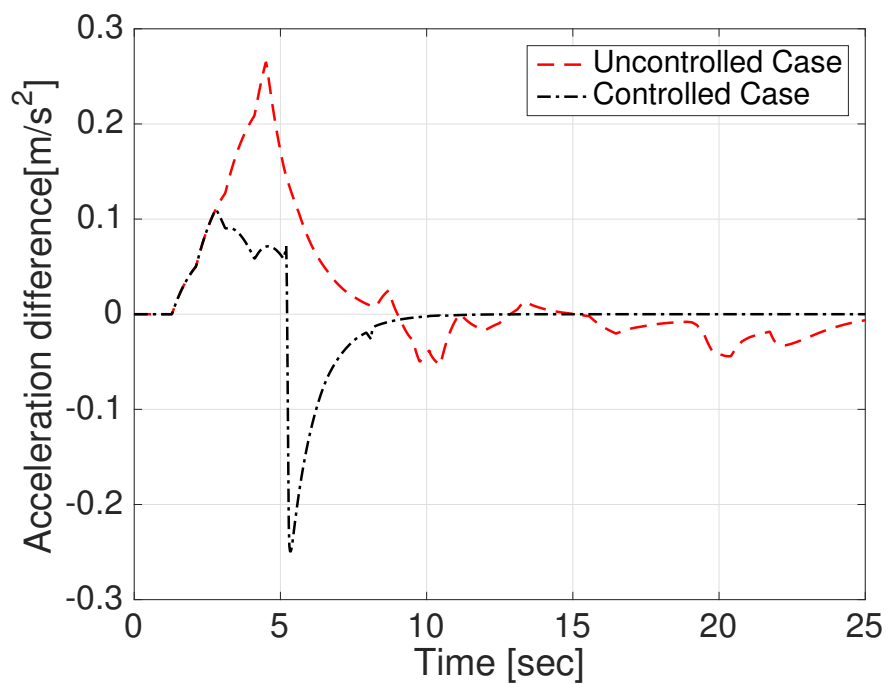

Figure 17: Simulation results of excessive acceleration under controlled case and uncontrolled case

for an electrified powertrain through hazard analysis and risk assessment, followed by a plant and fault modeling process to provide guidance in deter- 
mination of numbers of severity and controllability, which are important to determine ASILs in HARA.

Functional safety can be achieved by implementing effective diagnosis and fault tolerant control mechanisms so that once a component fault is detected, then the appropriate remedial actions are enabled to eliminate safety hazards to the humans. This paper presents the design of a model based diagnosis and fault tolerant control strategy based on structural analysis that leads to a systematic solution to the functional safety problems. This structural approach utilizes a system's structural model in matrix form and analyzes the redundancy of the model for fault detection and isolation. The method is very effective in analyzing fault diagnosability during early stages of diagnostic system design, and provides guidelines as to the design of diagnostic tests and residual generators.

In particular, this paper uses this structural analysis approach to provide diagnostic solutions to torque functional safety problem of pedal-by-wire systems in electrified vehicles, with a case study based on pedal stiction fault. The structural approach for FDI proves to be effective in detecting and isolating faults. With the help of FDI and FTC, the vehicle is capable of actively compensating for the driver delay in taking actions in front of faults, so as to avoid torque functional safety problem. By introducing structural FDI and FTC, the considered hazard can be mitigated according to its ASIL rating, maintaining the vehicle in a safe state. 


\section{Acknowledgment}

This paper is based upon work supported by the Department of Energy under Award Number DE-PI0000012. This paper was prepared as an account of work sponsored by an agency of the United States Government. Neither the United States Government nor any agency thereof, nor any of their employees, makes any warranty, express or implied, or assumes any legal liability or responsibility for the accuracy, completeness, or usefulness of any information, apparatus, product, or process disclosed, or represents that its use would not infringe privately owned rights. Reference herein to any specific commercial product, process, or service by trade name, trademark, manufacturer, or otherwise does not necessarily constitute or imply its endorsement, recommendation, or favoring by the United States Government or any agency thereof. The views and opinions of authors expressed herein do not necessarily state or reflect those of the United States Government or any agency thereof.

\section{References}

[1] ISO26262, road vehicle - functional safety, International Standard, Part 3 (2011).

[2] S. Christiaens, J. Ogrzewalla, S. Pischinger, Functional safety for hybrid and electric vehicles, SAE Technical Paper (No. 2012-01-0032.).

[3] R. Dardar, Building a safety case in compliance with ISO 26262 for fuel level estimation and display system, Master's thesis, Mlardalen Uni- 
versity, School of Innovation, Design and Engineering, Vsters, Sweden (2014).

[4] R. Palin, I. Habli, Assurance of automotive safety-A safety case approach, Springer, 2010.

[5] R. Palin, D. Ward, I. Habli, R. Rivett, ISO 26262 safety cases: compliance and assurance, in: System Safety, 2011 6th IET International Conference on, IET, 2011, pp. 1-6.

[6] J. Birch, R. Rivett, I. Habli, B. Bradshaw, J. Botham, D. Higham, P. Jesty, H. Monkhouse, R. Palin, Safety cases and their role in ISO 26262 functional safety assessment, in: Computer Safety, Reliability, and Security, Springer, 2013, pp. 154-165.

[7] J. Pollard, An examination of sudden acceleration, Tech. rep., U.S. Departmen of Transportation, National Highway Traffic Safety Administration (1989).

[8] G. Rizzoni, S. Onori, M. Rubagotti, Diagnosis and prognosis of automotive systems: Motivations, history and some results, in: Fault Detection, Supervision and Safety of Technical Processes, 2009, pp. 191-202.

[9] J. Gertler, Fault detection and diagnosis in engineering systems, CRC press, 1998.

[10] M. Blanke, J. Schröder, Diagnosis and fault-tolerant control, Vol. 115, Springer, 2003. 
[11] M. Krysander, Design and analysis of diagnosis systems using structural methods, Ph.D. thesis, Linköping University.

[12] M. Krysander, M. Nyberg, Fault diagnosis utilizing structural analysis, CCSSE, Norrköping, Sweden.

[13] M. Krysander, J. Aslund, Graph theoretical methods for finding analytical redundancy relations in overdetermined differential algebraic systems, system 1 (2005) x2.

[14] M. Krysander, E. Frisk, Sensor placement for fault diagnosis, IEEE Trans. Syst., Man, Cybern., Syst. 38 (6) (2008) 1398-1410.

[15] M. Krysander, J. Aslund, M. Nyberg, An efficient algorithm for finding minimal overconstrained subsystems for model-based diagnosis, IEEE Trans. Syst., Man, Cybern., Syst. 38 (1) (2008) 197-206.

[16] V. Flaugergues, V. Cocquempot, M. Bayart, M. Pengov, Structural analysis for FDI: a modified, invertibility-based canonical decomposition, in: Proceedings of the 20th International Workshop on Principles of Diagnosis, DX09, Citeseer, 2009, pp. 59-66.

[17] C. Svard, M. Nyberg, E. Frisk, Realizability constrained selection of residual generators for fault diagnosis with an automotive engine application, IEEE Trans. Syst., Man, Cybern., Syst. 43 (6) (2013) 1354-1369.

[18] C. Svärd, M. Nyberg, E. Frisk, M. Krysander, Automotive engine FDI by application of an automated model-based and data-driven design methodology, Control Engineering Practice 21 (4) (2013) 455-472. 
[19] C. Svard, M. Nyberg, Residual generators for fault diagnosis using computation sequences with mixed causality applied to automotive systems, IEEE Trans. Syst., Man, Cybern. A, Syst.,Humans 40 (6) (2010) 13101328.

[20] Z. Liu, Q. Ahmed, G. Rizzoni, H. He, Fault detection and isolation for lithium-ion battery system using structural analysis and sequential residual generation, in: ASME 2014 Dynamic Systems and Control Conference, American Society of Mechanical Engineers, 2014, pp. V002T36A005-V002T36A005.

[21] C. Sundstrom, E. Frisk, L. Nielsen, Selecting and utilizing sequential residual generators in FDI applied to hybrid vehicles, IEEE Trans. Syst., Man, Cybern., Syst. 44 (2) (2014) 172-185.

[22] C. Sundström, Vehicle level diagnosis for hybrid powertrains, Master's thesis, Linköping University (2011).

[23] J. Zhang, G. Rizzoni, Structural analysis for FDI of PMSM drive system in electric vehicles, in: Transportation Electrification Asia-Pacific (ITEC Asia-Pacific), 2014 IEEE Conference and Expo, IEEE, 2014, pp. 1-7.

[24] J. Zhang, H. Yao, G. Rizzoni, Fault diagnosis for electric drive systems of electrified vehicles based on structural analysis, IEEE Transactions on Vehicular Technology PP (99) (2016) 1-1. doi:10.1109/TVT. 2016. 2556691 .

[25] J. Zhang, G. Rizzoni, Q. Ahmed, Fault modelling for hierarchical fault 
diagnosis and prognosis, in: ASME 2013 Dynamic Systems and Control Conference, 2013, pp. 1-6.

[26] A. Cordoba Arenas, J. Zhang, G. Rizzoni, Diagnostics and prognostics needs and requirements for electrified vehicles powertrains, in: 7th IFAC Symposium on Advances in Automotive Control, 2013, pp. 524-529.

[27] J. Pollard, E. D. Sussman, An examination of sudden acceleration, Citeseer, 1989.

[28] N. H. T. S. Administration, et al., Technical assessment of toyota electronic throttle control (ETC) systems (2011).

[29] M. T. Kirsch, V. Regenie, M. Aguilar, O. Gonzalez, M. Bay, M. Davis, C. Null, R. Scully, R. Kichak, Technical support to the national highway traffic safety administration (NHTSA) on the reported toyota motor corporation (TMC) unintended acceleration (UA) investigation, NASA Engineering and Safety Center Technical Assessment Report (January 2011).

[30] S. Kane, T. Ellen Liberman, M. MacDonald, An examination of the national highway traffic safety administration and the national aeronautics and space administration engineering safety center assessment and technical evaluation of toyota electronic throttle control (ETC) systems and unintended acceleration, Safety Research \& Strategies, Inc.

[31] J. Zhang, A. Amodio, B. A. Guvenc, G. Rizzoni, P. Pisu, Investigation of torque security problems in electrified vehicles, in: ASME 2015 Dy- 
namic Systems and Control Conference, American Society of Mechanical Engineers, 2015.

[32] The two second rule, Road Safety Authority (Government of Ireland. http://www.rulesoftheroad.ie/rules-for-driving/ speed-limits/speed-limits_2-second-rule.html (2011).

[33] C. C. Macadam, Understanding and modeling the human driver, Vehicle System Dynamics 40 (1-3) (2003) 101-134.

[34] R. J. Jagacinski, J. M. Flach, Control theory for humans: Quantitative approaches to modeling performance, CRC Press, 2003.

[35] National highway traffic safety administration toyota unintended acceleration investigation, Tech. rep., NASA Engineering and Safety Center Technical Assessment Report (January 2011).

[36] Technical assessment of toyota electronic throttle control (ETC) systems, Tech. rep., U.S. Department Of Transportation, National Highway Traffic Safety Administration (February 2011).

[37] S. Kane, E. Liberman, T. D. F. Click, M. MacDonald, An examination of the national highway traffic safety administration and the national aeronautics and space administration engineering safety center assessment and technical evaluation of toyota electronic throttle control (ETC) systems and unintended acceleration, Tech. rep., Safety Research and Strategies (2011).

[38] M. Costin, R. Schaller, M. Maiorana, J. Purcell, R. Simon, P. Bauerle, 
J. Stockbridge, An architecture for electronic throttle control systems, Tech. Rep. 2003-01-0098 (2003).

[39] D. McKay, G. Nichols, B. Schreurs, Delphi electronic throttle control systems for model year 2000; driver features, system security, and oem benefits. etc for the mass market, Tech. Rep. 2000-01-0556 (2000).

[40] P. M. Frank, Fault diagnosis in dynamic systems using analytical and knowledge-based redundancy: A survey and some new results, automatica 26 (3) (1990) 459-474.

[41] A. Dulmage, N. Mendelsohn, Coverings of bipartite graphs, Canadian Journal of Mathematics 10 (4) (1958) 516-534. 


\section{Appendix A. Electric Vehicle Mathematical Model}

$$
\begin{aligned}
& e_{1}: \alpha=\alpha_{r e f}+f_{\alpha} \\
& e_{2}: T_{\text {eref }}=T_{a c c}+T_{b r k, e m} \\
& e_{3}: T_{a c c}=\frac{y_{\alpha_{1}}+y_{\alpha_{2}}}{200} T_{\text {max }, \text { axle }} \\
& e_{4}: T_{b r k, e m}=g_{1}\left(y_{\beta_{1}}, y_{\beta_{2}}, V_{v e h}\right) \\
& e_{5}: T_{b r k, f r}=g_{2}(\beta) \\
& e_{6}: \alpha \beta=0 \\
& e_{7}: T_{m}= \begin{cases}\frac{T_{a c c}+T_{b r k, e m}}{\eta_{g b}} & T_{e m, \min }<\frac{T_{a c c}+T_{b r k, e m}}{\eta_{g b}}<T_{e m, \max } \\
T_{e m, \max } & \frac{T_{a c c}+T_{b r k, e m}}{R_{g b}} \geq T_{e m, \max } \\
T_{e m, \min } & T_{e m, \min } \geq \frac{T_{a c c}+T_{b r k, e m}}{\eta_{g b}}\end{cases} \\
& e_{8}: F_{\text {total }}=\frac{T_{m} \eta_{g b}+T_{b r k, f r}}{R_{w}} \\
& e_{9}: M \frac{d V_{v e h}}{d t}=F_{\text {total }}-F_{L} \\
& e_{10}: y_{\alpha_{1}}=\alpha+f_{y_{\alpha_{1}}} \\
& e_{11}: y_{\alpha_{2}}=\alpha+f_{y_{\alpha_{2}}} \\
& e_{12}: y_{\beta_{1}}=\beta+f_{y_{\beta_{1}}} \\
& e_{13}: y_{\beta_{2}}=\beta+f_{y_{\beta_{2}}}
\end{aligned}
$$




\section{Appendix B. Electric Vehicle Equations with Pedal Fault Model}

$$
\begin{aligned}
& e_{1}: \dot{\alpha}=f_{f_{s t k}} \\
& e_{2}: \dot{\alpha}=\frac{d \alpha}{d t} \\
& e_{3}: T_{\text {eref }}=T_{a c c}+T_{b r k, e m} \\
& e_{4}: T_{a c c}=\frac{y_{\alpha_{1}}+y_{\alpha_{2}}}{200} T_{\text {max }, \text { axle }} \\
& e_{5}: T_{b r k, e m}=g_{1}\left(y_{\beta_{1}}, y_{\beta_{2}}, V_{v e h}\right) \\
& e_{6}: T_{b r k, f r}=g_{2}(\beta) \\
& e_{7}: \alpha \beta=0 \\
& e_{8}: T_{m}= \begin{cases}\frac{T_{a c c}+T_{b r k, e m}}{\eta_{g b}} & T_{e m, \min }<\frac{T_{a c c}+T_{b r k, e m}}{\eta_{g b}}<T_{e m, \max } \\
T_{e m, \max } & \frac{T_{a c c}+T_{b r k, e m}}{R_{g b}} \geq T_{e m, \max } \\
T_{e m, \min } & T_{e m, \min } \geq \frac{T_{a c c}+T_{b r k, e m}}{\eta_{g b}}\end{cases} \\
& e_{9}: F_{t o t a l}=\frac{T_{m} \eta_{g b}+T_{b r k, f r}}{R_{w}} \\
& e_{10}: M \frac{d V_{v e h}}{d t}=F_{t o t a l}-F_{L} \\
& e_{11}: y_{\alpha_{1}}=\alpha+f_{y_{\alpha_{1}}} \\
& e_{12}: y_{\alpha_{2}}=\alpha+f_{y_{\alpha_{2}}} \\
& e_{13}: y_{\beta_{1}}=\beta+f_{y_{\beta_{1}}} \\
& e_{14}: y_{\beta_{2}}=\beta+f_{y_{\beta_{2}}}
\end{aligned}
$$

